UNIVERSAL RXPOSITION, PARIS, $186 \%$

$$
\begin{gathered}
\text { MR. COWDIN'S } \\
\text { REPORT }
\end{gathered}
$$

ON

\title{
SILK AND SILK MANUFAOTURES.
}




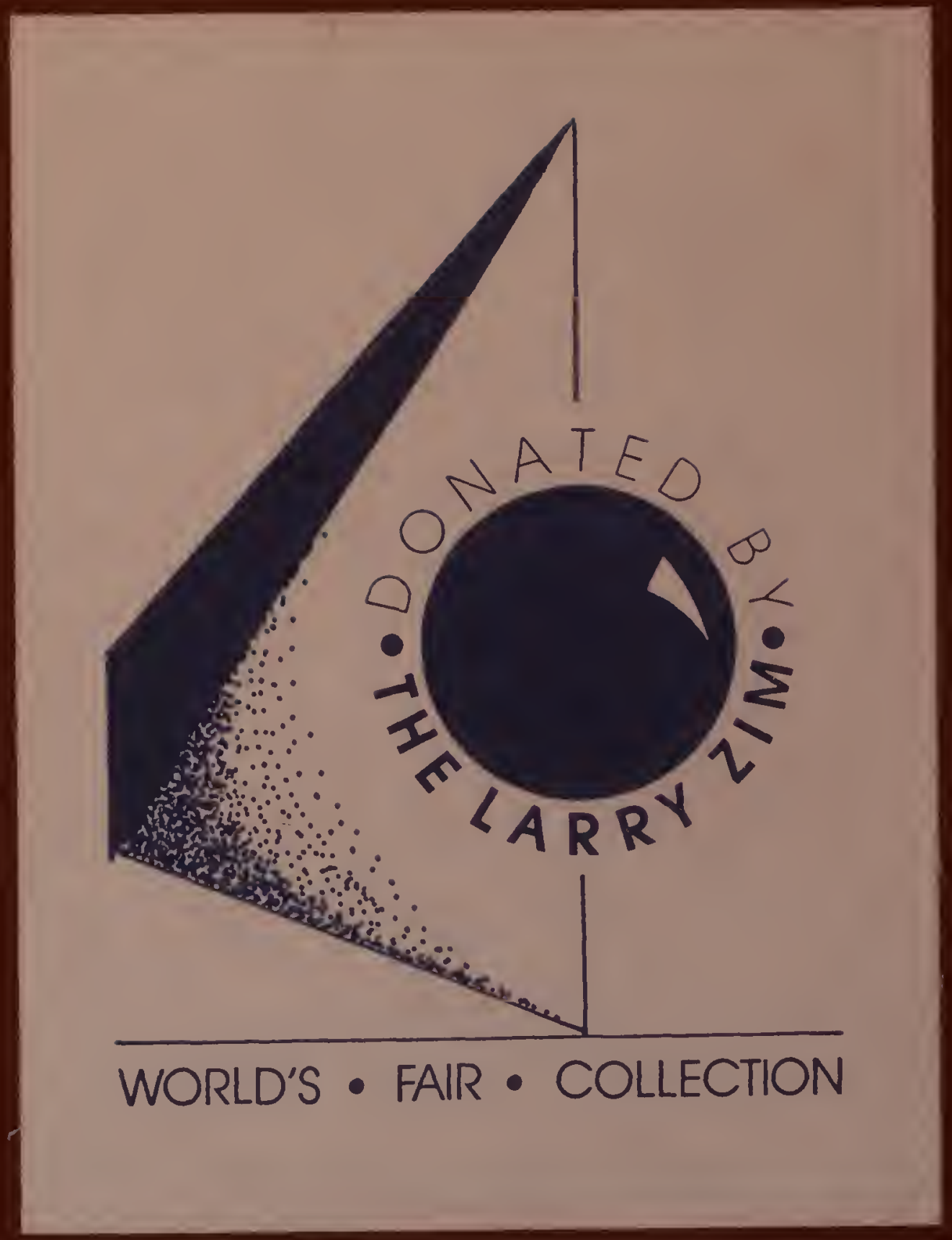


(1) 

Yamilton E. Jouls -

1868 

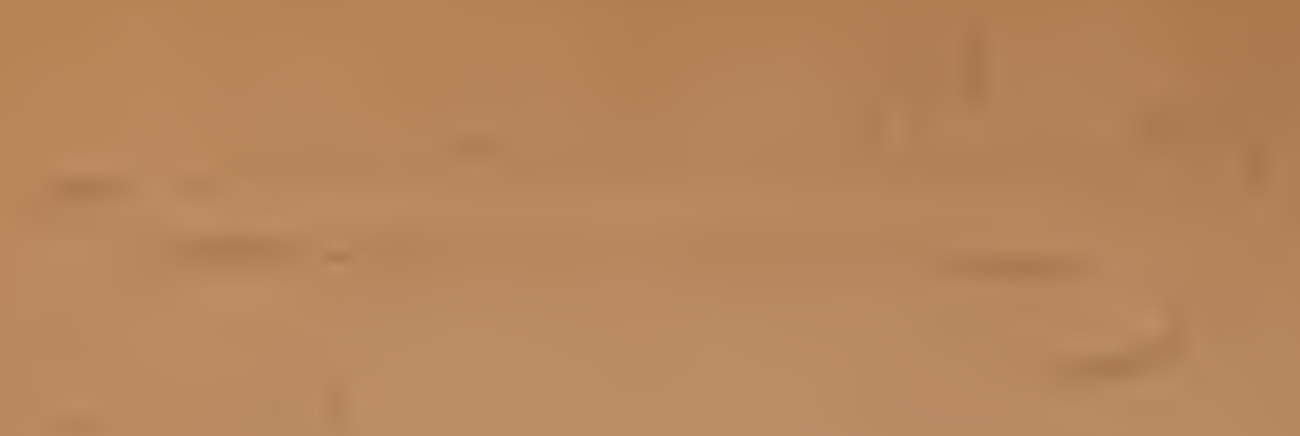

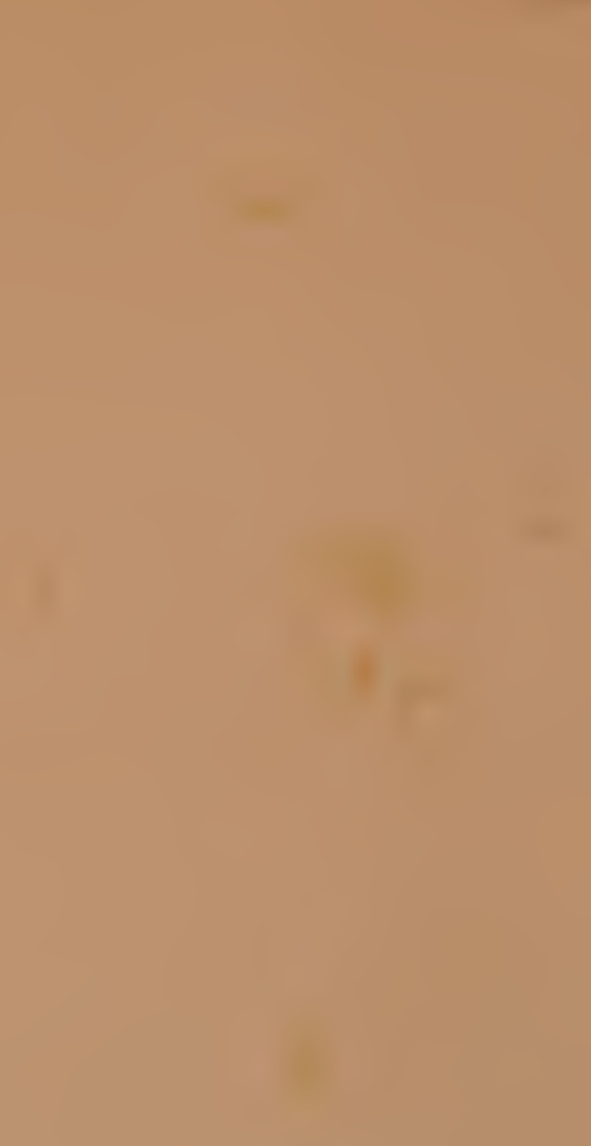

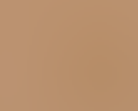

$x^{2}+x^{2}$

X

1 
UNIVERSAL EXPOSITION, PARIS, 1867.

\section{REPORT}

TO THE

\section{DEPARTMENT OF STATE}

ON

\section{SILK AND SILK MANUFACTURES.}

BY

ELLIOT C. COWDIN, UNITED STATES COMMISSIONER.

W A S H I G T O N, D. C. 1868 . 



\title{
M ESS A E
}

\section{FROM \\ THE PRESIDENT OF THE UNITED STATES,}

IN ANSWER TO

A resolution of the Houss of 18 th nltimo, transmitting report of Elliot C. Cowdin, Esq., commissioner to the Paris Exposition of 1867 . on silk and silk manufactures.

MARCH 26, 1868.--Read, referred to the Committee on Foreign Affairs, and ordered to be printed.

To the House of Representatives of the United States:

In answer to a resolution of the House of Representatives of the 18th ultimo, relating to the report of Mr. Cowdin, I transmit a report of the Secretary of State, and the document to which it refers.

WASHINGTON, March 25, 1868.

ANDREW JOHNSON.

\author{
Department of State, \\ Washington, March 25, 1868.
}

'The Secretary of State, to whom was referred the resolution of the House of Representatives of the 18th ultimo, requesting the trans. mission to that house of the report of Elliot C. Cowdin, Esq., commissioner to the Paris Exposition of 1867 , on silk and silk manufactures, has the honor to lay before the President the report thus called for.

Respectfully submitted:

'Tine Piresident.

WILLIAM H. SEWARD. 



\section{REPORT.}

Sir :-

The undersigned, Commissioner of the United States, and Member of the "Committee on raw materials and manufactures of great use, or displaying remarkable skill or merit," to whom has been specially assigned the subject of silk and silk manufactures, respectfully submits the following

\section{REPOR'T.}

Silk, hy its characteristic qualities and unchangeableness, as well as by the richness and beauty of its appearance, is, in relation to textile substances, what gold is to metals.

It is, of all filamentary substances, that which gives the finest, most durable, and most elastic threads. Its tenacity is about equal to that of good iron; that is to say, a thread of silk of the same size will support nearly the same weight before breaking, and the textile matter affords 
an elasticity superior to that of the mineral substance.

Silk consequently unites the most brilliant properties with the most solid qualities.

Its various excellent and advantageous characteristics have made it an ohject of research in all ages, by the different nations of the world.

China, even in our own day, the most important country for the production of silk, appears to have been its cradle, at the most remote epoch. The Chinese annals attribute to the Emperor Fan-Hi the merit of having employed silk in the manufacture of a musical instrument, of his own invention, 3400 years before the Christian era.

The Empress Si-ling-Chi was the first to invent silk tissues 2650 years before our era, which invention contributed so immensely to the prosperity of her country, that she was placed among the Chinese divinities, under the name of SienThsan; " and even now the Chinese Empresses offer annually solemn sacrifices to her meniory.

As it is the habit of the Emperor of China, once a year, to plough the earth, in order to add dignity and honor to agricultural pursuits, so, in

* This name means the first promoter of silk industry. 
like manner, the Empress, hy annually visiting the silk-worm nurseries and laboring with her own hands, encourages the production of this valuable commodity.

Two centuries before the Christian era, the Chinese carried on a commerce of silk with Persia, Greece, and Italy. Their caravans, or troops of dealers, were protected by military settlements or colonies.

The generic name given to this precious material has remained unchanged, except with a slight modification of the word. In fact, the French word soie or sill bears among them the name sec. The Mongols name it sirke. The Mantchoos, sirche. The Russians designate it by the word chek, and the Greeks by sez, etc.

Notwithstanding the antiquity of the use of silk, its nature was for a long time unknown, and its importation into the West was of recent date compared to its high antiquity in Asia.

The history of the introduction of the first eggs of the silk-worm into Constantinople during the reign of the Emperor Justinian, is well known.

The Chinese, determined to retain the monopoly of the silk industry, forbade the exportation of the eggs under penalty of death. 
They were, nevertheless, obtained, A. D. 552, by two Persian monks, who had lived a long time in China, as missionaries, and were acquainted with the rearing of silk-worms; stimulated by the gifts and promises of the Emperor Justinian, they succeeded in conveying a large number of eggs concealed in hollow canes, to Constantinople, where they watched their hatching and the development of the butterflies.

The breeding of silk-worms spread, however, very slowly in Europe. The Moors imported them into Cordova about the year 910. Greece and Italy undertook it in the 12 th century. From thence, this branch of industry passed to Marseilles. At the commencement of the 14th century, Pope Clement V. introduced it into Avignon. Under Henry IV., Sully established a silk-worm nursery in the Garden of the Tuiteries. Louis XIV. continued to encourage this enterprise in France, though with but slight success, so far as relates to the production of cocoons and the spinning of silk.

The weaving of silk goods with foreign thread had, on the contrary, already made marked progress in France, and had a great developinent, which it preserved even up to the revocation of 
the Edict of Nantes, after which period the weaving, as well as the spinning of silk, lost ground considerably.

The emigrants carried this beautiful industry into England, Germany, and Switzerland, and raised the most active competition against France, whose manufactures of silk remained in a lan. guishing condition up to the close of the great revolution at the end of the last century, and until shortly before the return of peace to Europe.

\section{RISE AND PROGRESS OF SILK INDUSTRY IN THE UNITED STATES.}

America was not insensible to the efforts made by other nations to appropriate to themselves the production of silk.

During the early periods of the colonization of Virginia, James I., on several occasions, advised with and encouraged the London company, in regard to the cultivation of the mulberry-tree, and addressed a letter to the company, in which he enjoined its members and exhorted the planters to apply themselves with diligence to the breeding of silk-worms, to establish silk-worm-nur'series and spinning-grounds, and to devote their activity 
rather to the production of this rich commodity than to that of tobacco, to which he manifested a profound aversion. Upon this advice, they planted a large number of mulberry-trees, but collected little silk in consequence of the difficulties resulting from the speedy dissolution of the London company.

However, the culture of the mulberry was resumed in Virginia about the year 1651 .

The tree was indigenous in the colony, and the enterprise was so far advanced in 1660 that the coronation robe of Charles II. was the product of the silk-worms of Virginia. But the steady advance of tobacco-culture caused the business to so decline, that it seems to have almost disappeared by the close of the century.

During the eighteenth century, efforts were made to introduce silk husbandry into all the American colonies. It had been started as early as 1718 with some success in Louisiana, then under the dominion of Spain. The most strenuous exertions were directed to Georgia. Private gifts co-operated with acts of Parliament, and its settlers were stimulated by grants of land to cultivate the mulberry and raise silk-worms.

In 1732 , artisans skilled in this industry were 
sent over from Europe. The French emigrant, who had charge of the business, proved treacherous and destroyed the machinery, eggs, and trees, and fled from Georgia. The Italian who succeeded him was more trustworthy, and some raw silk was soon exported to Europe. In 1735, a beautiful robe was made in England, of Georgia silk, which Queen Caroline wore on a great state occasion.

In 1749 , the export of cocoons reached 1,000 Ibs., and their product commanded the highest prices. A large silk establishment was soon erected in Savannah. The cocoons annually delivered to it in the years from 1758 to 1766 inclusive, ranged from 10,000 to $15,000 \mathrm{Hbs}$, and in the latter year they reached 20,000 $\mathrm{Jbs}$.

During the same period the annual export of raw silk ranged from $500 \mathrm{Hbs}$. to $1000 \mathrm{Hbs}$. At this period the silk culture was one of the most flourishing and profitable in the colony. But its success was of short duration.

After 1766 the government bounties were withdrawn, and this industry began to droop. The storm of the revolutionary war prostrated it. After the peace, the planters of Georgia turned their attention to the growing of cotton, and silk culture utterly and finally disappeared. 
* The experiment in Georgia-its rise, progress, and decline, are the history of silk culture in all the colonies.

Brief notices of some other colonies must suffice.

In South Carolina silk-growing was prosecuted hefore the revolution, and for a time flourished. The mother of the celebrated Pinckneys carried some silk, produced on her plantation, to England, where it was woven into tissues. Gowns were made of it and presented by her to the mother of young George III, and to the elegant Earl of Chesterfield. But the same causes that uprooted the business in Georgia, destroyed it in Carolina. It passed away in the advent of cotton raising.

Silk husbandry received early attention in Pennsylvania and New Jersey. The British Government aided it by liberal bounties. Dr. Franklin, while in Europe in 1750, sent home, for distribution, seeds, mulberry cuttings, silkworms' eggs, etc., and, with other distinguished citizens, gave it much encouragement.

In 1771, a silk establishment was set up in Philadelphia, which, during a series of years, received a large amount of cocoons. A lady of Lancaster County raised cocons from which a 
piece of silk of fifty yards was manufactured. From this a court dress was prepared for the Queen, who sent from Windsor Castle, in return, a handsome present to the fair donor on the banks of the Susquehanna.

Large mulberry groves flourished at Princeton, N. J., and cocoons of excellent quality were produced in encouraging quantities. But, as in the South, the convulsion of the revolution, unusually severe in Pennsylvania and New Jersey, prostrated this branch of industry; and, though efforts were made after the peace, to revive it, they were not specially successful.

Massachusetts and Connecticut took the lead in this enterprise in the East. It received the fostering support of the authorities. Governor Law, in 1747 , appeared in a silk coat and stockingss of home production. A few years afterwards, President Stiles, of Yale College, officiated at Commencement in flowing robes of Connecticut silk. In 1770, Boston and New Haven vied with each other in raising cocoons, and in spinning, dyeing, and manufacturing raw silk.

A flourishing manufactory of sewing-silk was established at Mansfield, Conn., before the revolution. Ipswich, Mass., was, at the same period, 
noted for its silk products; while the largest and finest mulberry nursery in the country was growing at Northampton. All these enterprises suffered by the blight which fell upon all industrial pursuits during the revolutionary war.

Silk husbandry and manufacturing had almost ceased to exist in the United States at the commencement of this century. Since then they have not kept pace with the advance in kindred pursuits. Nevertheless, they have always been prosecuted to an encouraging extent in various parts of New England, New York, New Jersey, and Pennsylvania. As, for example, Mansfield, already referred to, has done a large business in sewing-silks, and produced in 1839 five tons of the raw material. Washington, Pa., always kept up the business. It was introduced into the State Prison, at Auburn, N. Y., in 1841; and, the first year, the product of sewing-silk was about $\$ 13,000$. It was steadily increasing in the country when, some twenty-five years ago, its growth was checked by a disastrous speculative furor in the Morus Multicaulis shrub, which, for a few years, raged throughout the Union like an epidemic.

The reaction fell heavily upon the whole business, covering it temporarily with odium and 
ridicule. It has since been slowly recoverings from this season of delusion and folly.

In 1840, the product of silk raised in the United States was estimated at about 60,000 1bs., valued at $\$ 250,000$. In 1844 , it had increased to about $400,000 \mathrm{Hts}$., worth $\$ 1,500,000$. By the census of 1850 , when the effects of the speculative mania alluded to had culminated, the annual product was rejorted at only 14,763 1bs. Then it began to revive; and by the census report of 1860 , it appears that the manufacture of sewingsilks was carried on extensively in Connecticut, New Jersey, Massachusetts, Pennsylvania, and New York-the States being named in the order of the value of their products. The annual production in these States, including tram, organzine, etc., was placed at upwards of $\$ 5,000,000$. Ribbons were made to a small extent, as were also silk stuffs. But, aside from sewing-silks, the chief silk manufacture consisted of ladies' dress-trimmings, coach-laces, etc., of which the cities of Philadelphia and New York are reported as producing about $\$ 2,300,000$ ).

Since 1860, the business in all its departments has made steady progress; and the current period is more favorable than any previous one for its 
ei: $\lrcorner$ rgetic prosecution. Our country is specially fitted for silk culture. The experiments in Georgia and South Carolina proved that their soil and climate were peculiarly suited to it. May we not hope that, after a lapse of eighty-five years, it will be renewed in those States, and be prosecuted successfully, not only there, but also in all the middle latitudes of the Union, whose rich soil, genial sun, and dry atmosphere are admirably adapted to the cultivation and manufacture of this beautiful and useful article?

But, though the possibility of the success of this kind of industry has been demonstrated in a great number of localities in America, it is probably to the Pacific Coast that we are to look for its greatest triumph.

Among the finest cocoons exhibited at the Exposition, were specimens from California. They were perfect in form, and remarkable for their white, silvery hue. The soil in the valleys of California is proverbially fertile, and mulberry. trees are produced of the richest and most luxuriant growth. Its dry, warm, equable climate make it vastly superior for silk hushandry to France or Italy. In European countries, the rain 
and dampness destroy a much larger percentage of the grubs than on the Pacific Coast.

An intelligent and enterprising French emigrant, who is enthusiastically prosecuting this industry at San José, declares that the humidity and electricity of Europe destroy fiom 25 to 75 per cent. of the silk-worns, while under the dry, elastic skies of California few ever perish. These considerations, in a measure, compensate for the higher wages of American labor.

There are other savings in this industry, as compared with its prosecution in Europe. In California, there is no necessity for artificial heat to hatch the eggs. To transfer them from the cellar to the garret, and expose them to the beating of the sun's beams on the roof is sufficient. Nor need the cultivator run the risk of the "baking" process, so liable to dim the lustre of the silk. The powerful rays of the sun for a few hours will stifle the chrysalis, render the cocoon ready for the spinner, and preserve the brilliancy of the material.

California eggs are already highly valued by foreign silk-growers. Cultivators are diffusing them along the Pacific coast. A considerable capital is invested in the silk business. The largest cocooneries are at Santa Barbara. 
An important experiment is now being made there by energetic parties, who have already 10,000 thrifty mulberry-trees, and have produced the present year (186 $\tau$ ) upwards of 300,000 cocoons of excellent quality.

An enterprising company is erecting an extensive factory at San José, to be furnished with all necessary machinery (including some forty looms) for producing taffetas in all colors, and of the best qualities.

May we not hope that the day is not far distant when the plains that slide down from the western base of the Sierra Nevada will become as famous for beautiful silks as its gorges have long been for precious metals, and its valleys are now becoming for cereals?

The nationality of the Commission, from which this report emanates, must furnish the excuse for dwelling so long at the outset upon the subject of silk culture and manufacture in the United States. It will be resumed in brief terms near the close of the report.

As pertaining to the American branch of this subject, it may be stated, in this connection, that silk culture was recently commenced in the Republic of Ecuador. Its soil and climate are 
said to be wonderfully adapted to the growtin of the mulberry and the rearing of the grub, especially in the neighborhood of Quito.

The first eggs were imported from France in 1859. The first exported to France was in 1865 , where the eggi were highly esteemed, and were wholly exempt from the peculiar disease prevailing in Europe. Like its vegetation, silk culture in Ecuador can flourish the year round.

The food required by the worms is only half as much as in Europe, because of the superior richness of the leaves, and the more favorable condition of the climate. The number of mul. berry-trees now growing in the republic is nearly a million. Labor is abundant and excessively cheap. The promoters of this enterprise in Ecuador indulge sanguine hopes of success. No doubt, considerable portions of South America are well adapted to this department of industry.

\section{REARING OF SILK-WORMS.}

Numerous observations made by French and Italian scientific agriculturalists and silk-husbandmen, show :

1st. - That the culture of the mulberry-tree, and the breeding of silk-worms, are possible up 
to a limit very far advanced northwards,- - a limit fixed by the frequent occurrence of a temperature of 77 degrees Fahrenheit.

2d. - The limit of the culture of the mulberry does not pass beyond that of the cultivation of the grape, and the culture of the former is possible wherever the latter will thrive.

3d.-The mulberry can be raised upon the sides of the mountains of Europe, up to the point where the mean temperature of the year is 49 degrees Fahrenheit.

4th.-Climates, habitually stormy, are not congenial to the breeding of the silk-worms.

5th.-Places afflicted with fevers (proving the existence of marshy emanations) are pernicious to the silk-worms.

6th.-This industry is to be considered rather as an adjunct to a large farm, than as a chief occupation.

To these principles, given as the natural conditions necessary or hurtful to the industry of silk-husbandry, are to be added the not less important questions of the price at which it returns from the hand of the workman in each locality, and of the abundance or scarcity of manual labor. We must, however, 
remark that the insufficiency of worms and their high price during more than ten years, in consequence of the malady of the precious grub in Europe, allow a remuneration suffi. ciently high to corer the expenses of the dearest hand-labor, especially if we consider that the duration of care and attention, which the harresting of the worms demands, does not exceed six weeks, counting from the day of hatching to a period after the warehousing of the cocoons, which latter, according to the best systems in use in Italy and France, can be reeled during the whole year.

\section{PRODUCTION OF RAW SILK.}

The production of the cocoons is essentially an agricultural industry; and the winding off the cocoons into raw silk may be considered as semi-manual, and, in part, automatic. All the other transformations of the silk, from the throwing to the working of stuff's, are entirely mechanical.

It can hardly be possible that, henceforth, the Uniter States will not take a large share in the immense industrial and commercial morement to which silk has given rise in the world. 
Certain countries, such as Italy and France, and the oriental nations in general, employ themselves with all the transformations of silk, from the culture of the mulber'ry, and the breeding of the worm, to the manufacture of tissues.

England (and others follow her example to a limited extent), although not producing silk on her own soil, yet carries on a most important commerce in that article, by means of her colonies and powerful marine. She developes, with equal activity, the spinning or throwing of silk thread, and the weaving of silk goods.

In a word, nations, such as the United States, Switzerland, and Northern Germany, which are almost exclusively manufacturer's, confine themselves to the transformation of silk bought in markets more or less distant.

The aptitudes of manufacturing nations change, or are materially modifier, from time to time. Russia, for example, could but recently hardly be ranked among manufacturing nations.* The people of that great empire are now malking,

* The culture of the mulbory-tree, the introduction of which into Russia dates from the period of Peter the Great, remained without any great results up to the commencement of the present century. 
not only rapid progress in the industrial arts, but they have adranced in the south of Russia, on the Caucasus, eren to the breeding of silk. worms.

The production of the silk-worm in that country, since the annexation of Trans-Caucasian Assia, for example, has been three-fold, though the silk is far from being worked with the requisite care, it being generally irregular, and suited only to the most common productions.

In 1865, this part of Russia exported nearly 30,000 kilo's, or 66,155 1bs. of silk, " representing a sum of about $1,560,000$ fiancs $(\$ 312,000)$, that is to say, at the price of about 52 francs the kilogramme, while that of France and Italy sold for at least double that price. It is thought that the total silk production of Russia amounted to ahout 88,000 kilogrammes, or 194,05̃ 1bs., estimated at a value of about $4,576,000$ francs $(\$ 915,200$.

This result is far short of the limit which

* The metrical systen being in use in most of the countries from which we have derived our information, and constantly tending to extend itself more and more, especially since the Triterutiomal Conference at Paris, in which our countryman, Mr. Aannel B. Ruggles, bore so distinguished a lart, we have thought it useful and proper to retain, in part, for the numbers cited, the frane as the unit of money, and the kilogramme as the unit of weight. 
may ultimately be attained both in regard to quantity and price.

Germany and Switzerland have the same tendency, while France, the difierent states of Italy, and Spain, in consequence of the scourge which attacked the production at its source some years ago, are becoming almost entirely manufacturing countries, and benefit India and the extreme East by their increasing wants. The United Kingdom of Great Britain alone seems to profit by fluctuations so unfavorable to the rest of Europe, and even to America.

English ships go to collect in China, in Japan, at Calcutta, Bombay, etc., the eggs, or graines, cocoons, silk, and the waste, to sell again. After having first directly supplied her own manufactories, the surplus is disposed of to her neighbours in Europe; she thus profiting by the transport, warehousing, commissions, hrokerage, etc.

Silk forms one of the principal articles of commerce in the business transactions of Eng. land with the extreme East.

The following table will show, as nearly as can be ascertained, the value of the raw silk pro- 
duced annually, in the various countries of the earth, and its rast importance as an element of national wealth:

Asia $\$ 141,000,000$

Europe.

$73,480,000$

Africa

220,000

Oceanica

120,000

America.

80,000

Total

$\$ 214,900,000$

These amounts may be divided as follows, viz:

Chinese Empire. $\$ 81,200,000$

Japanese Empire

$17,000,000$

Persia

$5,000,000$

The Islands of Asia Minor.

$5,200,000$

Syria

$1,800,000$

Turkistan, independent (in Asia),

$1,400,000$

Turkistan (in China),

400,000

Corean Archipelago.

100,000

France

$25,600,000$

Italy

$39,200,000$

'Turkey in Europe.

$7,000,000$

Spain and Portugal.

$3,200,000$

Pontifical States.

$1,300,000$

Greece-Ionian Islands.

840,000

Morocco, Algeria, Tunis,Mediterranean Coast

Basin of the Danube, Austria, Bavaria, Hun-

India gary, Servia.

300,000

$1,280,000$

$24,000,000$

America

80,000

Total

$\$ 214,900,000$

These figures have been greatly reduced during the last few years, so far as concerns the production in Europe. That difference, however, 
was made up by the quantities received firom China, India, Japan, and the Levant.

But those exotic silks are far from heing as highly esteemed or as valuable as those of Europe.

The modification in the relative value of silk which has taken place during a century is worthy of note.

A century ago, nearly all the silk, or at least five-sixths of the quantity manufactured by French fabricants, came from foreign countries, from the Levant, firom Persia, Sicily, Italy, and Spain.

The other sixth only was produced in the south of France. The mean price of French silk was 15 firancs the livre, or 30 fiancs the kilogramme $\left(2 \frac{1}{5} \pi x\right)$. Exotic silks were much dearer. The most common foreign raw silk, that of Greece, then brought 120 francs the kilogramme, China and India silks 240 francs, and that of Italy was valued at firom 500 to bin) firancs.*

But by degrees French silk improved to such

* These are the prices as published in the price-current of the Amsterdam market, where, at that period, the greatest quantity of foreign silk was sold. 
an extent, that in the early part of this ceutury the price advanced to 70 francs the kilogramme. This rate was maintained almost without variation up to the year 1840, while foreign products were depreciated to such a degree that the very best quality from the Levant and from Persia sold at $4^{\prime \prime}$ francs, and the waste at 32 francs.

Italy, during this period, maintained the elevation in its prices, on account of the very excellent quality of its silks. That was, nevertheless, surpassed by the French silks, which finally rose from the last to the first rank, which they still maintain.

The raw silks of France, of the first quality, at a later period brought 150 francs, while those of the hest kind from Italy realized hardly $1(10)$ francs.

These results are due entirely to the progress in French manufactures, which has largely contributed to the extraordinary development of the silk industry that has occurred in that country.

This specialty of silk industry has given to France the importance that the cotton industry has to England.

In this connection, it may be profitable to give a rapid sketch (so far as data at hand will permit) 
of the progressive development of silk culture and manufacture in the principal countries of Europe and Asia. The amounts are given in round numbers, and, though obtained from trustworthy sources, may be liahle to some corrections. As first in importance we hegin with France.

PROGRESSIVE DEVELOPIENT OF SILK INDUSTRY IN FRANCE.

In 1789, France produced $1,000,000$ tbs. of raw silk. Near the close of the century she consumed about $1,200,000 \mathrm{Hbs}$. of silk thread, from which she manufactured from $\$ 3,000,000$ to $\$ 4,000,000 *$ (fifteen to twenty million francs) of tissues.

Of this she purchased about $\$ 1,400,000$ (seven million francs) from other countries.

The stock of stuff goods consequently ainounted to from $\$ 4,400,000$ to $\$ 5,400,000$ (twenty-two to twenty-seven million francs), of which France exported about one-half to foreign countries.

In 1812, France produced 600,000 1bs. of raw silk, and 340,000 tbs. of organzine, valued at $\$ 5,000,000$. The same year she imported 900,000 tbs., valued at $\$ 6,750,000$.

\footnotetext{
* Dollars at gold valuation in all cases.
} 
In 1820 , it is estimated that French manufacturers transformed $\$ 10,000,000$ (fifty million francs) of materials, of which one half was furnished by the Southern Departments. The goods produced from these materials represented a value of more than $\$ 20,000,000$ (one hundred million francs), of which $\$ 14,000,000$ (seventy million francs) were consumed at home, and $\$ 6,000,000$ (thirty million francs) were exported.

In 1812, the silk looms, in seven of the prin. cipal towns of the empire, numbered 27,000. In 1824, Lyons alone had nearly 25,000. In 1839, the number in Lyons had increased to 40,000 , and in the whole kingdom to 85,000, employing about 170,000 workmen. In the latter year, the entire production was estimated at $\$ 46,300,000$.

In 1850, the business had largely increased. The value of raw silk grown in the kingdom was $\$ 28,000,000$ (one hundred and forty million francs). The amount employed, $\$ 50,000,000$ (two hundred and fifty million francs); the amount imported being $\$ 22,000,000$. The silk goods produced were valued at $\$ 75,000,000$ (three hundred and seventy million fiancis), of which, about one-third were consumed at home, and two-thirds exported. 
In 1855 , the value of silk goods produced was estimated at $\$ 106,500,(00)$, of which about $\$ 26,500,000$ was imported. The home consumption was $\$ 35,000,000$, and the export about $\$ 71,500,000$. The number of silk looms in the empire was about 225,000. The number of persons engaged in this industry was upwards of half a million.

In 1860, the value of French silks amounted to upwards of $\$ 140,000,000$ (seven hundred million francs), and yet this was not sufficient to supply the demand. France purchased in foreign countries $\$ 40,000,000$ (two hundred million francs), chiefly of piece goods, velvets, and ribbons. Of this $\$ 180,000,000$, France exported about $\$ 110,000,000$ (five hundred and fifty million francs).

These totals were reduced at the outbreak of the American rebellion. France restricted to a marked degree her purchases of silks.

The United States imported from France, of silk tissues alone, in $1859, \$ 27,600,000$ (one hundred and thirty-eight million francs); in $1860, \$ 20,800,000$ (one hundred and four million francs); but in 1861, only $\$ 5,000,000$ (twentyfive million francs). 
Subsequently, the business increased; the Lyons' exports of silk goods to the United States in 1865 amounting to $8.9,916,(4)(1)$, and in 1866 to $\$(6,1)(n,(n)$. Though the rebellion has heen suppressed, the fiscal measures resulting therefrom still have their effect upon the silk husbandry and manufacture of France, operating, as they do, at the same period with the scarcity of indigenous silk, and the prevalence of the nysterious: disease among the silk-worms, which has hy no means disappeared, and to which special reference will be hereinatter made.

RISE AND PROGREAS OF GILK INDTATRY IN GREAT BRITAIN.

When the Duke of Parma sacked the City of Antwerp in 1585, its silk artificers fled to Lngland, carrying with them their experience and skill in this novel branch of industry. It was encouraged by the English Government. But, the humid climate being unfavorable to the rearing of the grub, it was not specially successtul.

On the revocation of the Eslict of Nantes, in 1685$, some 75,006$)$ of the most skiliful artizans of France took refuge in Treat Britain, among whom were a large body of silk weavers, who 
settled in Spitalfields (then a London suburb), and, under the fostering care of the crown, they and their children plied their vocation with success for a century and more; some of their descendents remaining in the same locality to this day.

For thirty or forty years after this immigration, England was wholly dependent on foreigners for organzine silk-thread. But, in 1718, Mr. Lombe, an English capitalist, visited Piedmont, disguised as a common laborer, took sketches of silk-throwing machinery in use there, and, on his return, erected an extensive mill at Derby, which produced more than three million yards of organzine per day.

For many years, raw silk was largely imported; acts of Parliament were passed from time to time stimulating its manufacture, and the husiness was steadily advancing, when, in 1764 , on account of low wages, scarcity of work, and the preference shown for French silks, the weavers of Spitalfields, and the silk operatives of other localities, assembled in a tumultuous manner, and petitioned parliament for the total prohibition of foreign-wrought silks. The commotion was kept alive by combinations of operatives for several 
years, till, in 1772 , it broke into open riots, which convulsed London many days, the final result being the passage of prohibition laws, which, after trial, proved unsatisfactory.

This system of prohibitory legislation continued till 1824. A high English authority has declared that "the manufacturer, depending upon the protection of Parliamentary restrictions on foreigin competition, rather than on his own skill and exertions, was not anxious to discover and introduce improvements into the manufacture." And he states that, "since the change of system, the imports of the raw material, and the exports of the manufactured article, have rapidly increased."

In 1825, the English silk-looms numbered ahout 24,(0)(1). In 1855, they had increased to more than 110,(1)(1), consuming ahout 5,500,000 pounds of thrown-silk, and producing goods to the value of nearly $\$ 45$, (n)(n, (n)(), besides a considerable amount of spun-silk, and goods of which silk constituted a part.

In 1855, England consumed, of her own silk manufactures, more than $\$ 35,(10)(1,(1)(1)$, while she imported about $\$ 2(),(1)(),(1)(1)$. 
In 1860 , the value of her silk manufactures was estimated at some $\$ 90,000,000$. On account of the extreme dampness and chilliness of her climate (of which mention has been made), she raises no silk-worms, but imports the raw material. In 1856 , the value of her imports of raw silk was (omitting fractions) $\$ 32,000,000)$, and in 1857 , $\$ 58,000,000$. It fell off in 1858 , on account of the "panic," but again revived. Nearly one-half the amount of the raw material came from China, and a large share of the balance from her East India possessions.

During the three years just mentioned, England imported $\$ 13,000,000$ of thrown-silk; more than oue-half being from France, and nearly onethird from China.

In 186(), the British consumption of raw and thrown-silk was 9,421$), 417 \mathrm{fbs}$; in 1861, 8,125,982 Ths.; in 1862, 9,706,202 1bs.; in 1863, 8,182,645 tbs.; in $1864,7,541,758$ 1bs.; in $1865,6,492,7211$ 1bs.; and in 1866, it was but 5,273,767 1bs.

In 1823, Great Britain exported of silk goods only $\$ 702,000)$; in 1844 it exported $\$ 3,682,000$; in $1856, \$ 14,800,000$; in $1858, \$ 11,950,000$; in $1861, \$ 11,560,900)$; in $1865, \$ 10,886,000$. 
Thus we see that this great manufacturing nation, although deprived of the capacity to successfully produce the raw material, by its uncongenial climate, has long prosecuted a large business, in the transformation of this beautiful article, though now seriously checked in many branches of its silk industry, by the effect of the recent treaty with France.

What an instructive lesson is thus taught to the citizens of our country, where everything combines to render the prosecution of this industry preëminently successful.

OTHER EUROPEAN COUNTRIES.

Italy was early famous for its silk-culture and manufactures. In Milan and vicinity, in the year 1800 , about 2,000,000 tbs. of raw silk were said to have been collected. In 1825, the quantity was estimated at 2,700,000) $\mathrm{Hbs}$., valued at $\$ 10,000,000$. In 1858 , at $5,400,0000$ 1bs., worth $\$ 30,000,000$. In 1825 , Piedmont produced about $1,500,000$ 1bs. of raw silk, of the very highest quality. In the same year 'Tuscany', Naples, the Romagna, and Calabria produced $1,500,(1)(10) \mathrm{Hts}$., also of excellent quality. 
In 1851, an Austrian official document stated the production in the Austrian dominions of Italy at $\$ 21,700,000$ in raw silk, and $\$ 14,200,0000$ in manufactured silks.

In 1855 , the total of both kinds of silk in the whole Italian peninsula was stated at upwards of $\$ 60,000,000$. A considerable portion is consumed at home, and the remainder exported, chiefly to Germany, France, and England.

Spain produced, in 1842, about 2,000,000 tbs. of raw silk, three-fifths of which was raised in Valencia. About 40(0,(0)(1) 15s. were manufactured at home, and the rest exported. The Spanish cocoons are excellent, but much of the reeling is defective. Valencia silks, where great care has been taken in the manipulation, are famous for their magnificence.

In Prussia, silk manufacture is rapidly increasing. The number of looms, in 1831, was 9,000 ; in $1837,14,000$; in 185525,000 ; and in 1865 , not less than 40,000 . In the Exhibition were superb silks, velvets, velvet ribhons, black silkribbons, mixed and unmixed silk fabrics of various descriptions, from Crefeld, Elberfeld, Viersen, and vicinity. The waters in that locality, especially those of the Wupper, hold in 
solution salts, specially adapted to secure permanence and brilliancy to the colors employed in manufacture.

Austria is engaged somewhat extensively in silk manufacture; but since she relinquished her Italian dominious, her total production will naturally be greatly diminished.

The product of Switzerland, in 1858, was placed at $\$ 20,000,000$.

The "Collective Exhibition of the Zurich Manufacturers" of black and colored silks-plain and figured, and the "Collective Exhibition of the Basle sitk ribbon manufacturers," as shown in the Exposition, evince the progress and perfection to which Swiss skill in silk industry has now attained.

Russia has already been alluded to. After France and England, the nations that come in the order of their importance, in respect to silk manufactures, are Switzerland, Prussia, Austria, Italy, and Spain.

France maintains a great superiority over all in her rich and artistic productions. But, in plain goods, and those of a secondary quality, she finds serious rivalry in British, Swiss, and German industry. Switzerland is becoming re- 
markable for her activity, her constant progress, and her improvements in material interests.

In a subsequent part of this report, the occasion will be embraced to examine the improvements she brought to the Exposition, since there is a great analogy between the situation of the industrial genius of that republic, and the social and manufacturing condition of the United States.

ASIATIC COUNTRIES AND AFRICA.

China raises, manufactures, consumes, and exports a vast amount of silk.

It is impossible to estimate the quantity consumed at home. A high authority declares, that of her four hundred millions of people, a large proportion, excepting the lowest classes, are clad, more or less, in silk fabrics. She exported to England alone, in 1858, nearly 10,000,000 tbs.

In the East India Company's possessions the product is large. In 1857, they exported to England about 4,500,000 15.s. Persia produced great quantities, much of which is consumed at home. The amount raised in Syria and Asia Minor is some 2,500,000 tbs. per aunum, of which a large share is exported to France and England. 
Reference to other Asiatic countries of inferior importance in this particular, is omitted.

Silk has long been produced, in small quantities, along the African shores of the Mediterranean.

England exports some of the raw material from Egypt, but the greater share of the production of the Nile region is consumed at home. Tripoli produced, in 1842, about 130,000 tbs. The Islands of Egypt and Crete raised, in 1859, some 50,000.

SPECIALITIES, EMBRACED BY SILK INDUSTRY IN THE EXPOSITION AND IN PRACTICE.

The labor in silk comprises seven distinct branches, forming as many different industries, even when a single manufacturer conducts several in one establishment. These specialities are:

1st.-The breeding or rearing of silk-worms, called in France the art of the magnanier, or silk-worm breeder. This word comes from magnan, the name given to the grub of the white mulberry in the south of France.

The appellation magnanière, or silk-worm nursery, is given to the locality where the worms are hatched, fed, and attended to from their birth till they have formed their silky envelope or cocoon.

These silk-worm nurseries are generally estab- 
lished in localities or countries favorable to the cultivation of the mulberry-tree, of whose leaves, and white fruit especially, the worm is particularly fond; also where the temperature is regular and moderate. Nevertheless, this last condition is not indispensable.

It is replaced artificially, by special means of warming and ventilation, so as to maintain, at will, constantly, the temperature between 70 and 75 degrees Fahrenheit, and thus be able to breed numerous little grubs. (One ounce, or thirty grammes contains about 40,000, while from twenty ounces 800,000 have been obtained at a time in the same place.) This result is arrived at chiefly by watchfulness in ventilation, in removing the vitiated air and replacing it by pure air.

The art of the silk-worm breeder embraces what is called "the fabrication of the graine," or, more correctly, of the eggs to be used in the reproduction.

The cocoons designed for this function are the only ones whose chrysalis or grub is allowed to be transformed into the butterfly.

These are moistened, and then the grub opens one of the lengthened extremities of the cocoon, and issues from it. 
Then the grubs are collected by pair's, male and female, to permit fecundation before the laying of the eggs.

These fécomiés, suspended on paper or cloth, are subsequently put aside, until the following spring, in an atmosphere of even temperature, and sufficiently low, like that of cellars.

This part of the art of the breeder, so simple in appearance, demands special knowledge and great care, particularly at this time when it is so difficult to procure eggs free from the epidemic now raging among the silk-worms.

2d. The second specialty in this industry is the filature, or reeling of the silk from the cocoons into the threads known as raw silk, and composed of fibres of a certain number of cocoons, according to the size of the thread required. It is a most delicate, untwisted product, but wanting in luster on account of its containing some twenty-five per cent. of gum.

3d. The throwing of silk, or the process of putting the raw silk into the threads required for the different kinds of wearing.

It is at the "throwing" that the threads are formed that figure so conspicuously at the Exposition, and also in commerce, under the names of singles, trams, and organzines. 
There are also other kinds of thrown silk known as marabouts, grenadines, crpêe, soie ondée, etc., which are twisted differently from trams and organzines, for special purposes.

Let us look, for a moment, at the comparative value of each of these descriptions.

The singles are the raw silk after the first twist.

The tram, or woof, is obtained by the union of two or more threads of raw silk slightly twisted.

The organzine, from which generally the warp is made, is the result of two singles twisted together.

A product of a peculiar nature, frequently used in the manufacture of trimmings, is the fil guipé. It is composed of one or more straight threads, around which is rolled a spiral threarl, the interior being generally of indifferent material, and the thread rolled around is composed of silk, gold, or silver.

4th. The dyeing constitutes an important specialty, requiring the greatest possible delicacy and skill; pure water being essential to success.

5 th. The preparation of the threads for the loom is another separate and essential branch, requiring care and attention. 
6th. The wearing embraces in itself alone several sub-divisions, namely: The wearing of plain and cut silk goods, the wearing of relvets, of figured stuffs more or less rich, the knitting of various articles, and the fabrication of silk blondes or laces.

THE SPINNING OF WASTE SILK.

7th. The preceding processes yield a certain quantity of waste, varying with the nature of the operations and the qualities of the products.

This waste is, in its turn, transformed from the raw state, where, after having been cleaned from the gummy matter, chiefly by mechanical means, it presents a close analogy to the strippings and windings of cotton and combed wool.

These processes are the basis of great industries which flourish in England and on the Continent.

The threads thus produced vary in value from 30 to 60 francs the kilo, according to their fineness and quality.

These branches of industry are now carried on, to some extent, by American manufacturers. 
EXAMINATION OF THE POSITION OF EACH OF THESE INDUNTRIEN, AND THEIR PROGRESS AS MANI-

FESTED IN THE EXPOSITTON.

In the art of silk-worm breeding, the question of first importance consists in the means of obtaining the graines or eggs. Grood eggs bear an exorbitant price. They are worth at the rate of 300 francs the kilo; and still they cannot always be produced, guaranteed against the prevailing malady, except from Japan.

The States of South America appear to enjoy the same immunity.

At the commencement of the prevailing epidemic (about the year 1846), other countries furnished healthy eggs, but their exemption did not continue after the second or third generation.

Thus it is, that the United States have been led to put all silk producing countries under contribution.

Will the eggs of Japan and of South America, at the present time so much sought after, escape this degeneracy, of which, despite the numerous investigations, we as yet do not know the cause?

But if the cause remains concealed, the preventive means begin to be more clearly established. 
The following method is generally admitted and recommended by men recognized as the most competent judges, and since it is the combined result of great experience and observation, it will be read with interest in all countries which desire to encourage the culture of the silk-worm :

1st. It is of the greatest importance to choose for re-production cocoons of the largest size, and those the most successfully reared and least affected with the malady during the course of their derelopment. These cocoons are recognized by the regularity of their form, the roundness of their extremities, the fineness of grain on the surface, and the solidity and thickness of the layer's or silky enrelopes.

The male cocoons differ from the females by their shape and size: the former are smaller than the latter, and present a carity upon their back. The latter are larger, presenting the figure of an olive, or the egg of a small bird.

The color of these cocoons ought to be of a golden yellow, after collecting, and should exhibit no spot or stain of any kind.

In the same breed, the heariest cocoons are, in general, those which offer the grreatest chance of affording the best reproductions. 
'Then, after having put a certain number of male cocoons on one side, and of female on the other, weigh both parts to find the average weight of each, and every time that this average weight is exceeded, there is a presumption that excellent cocoons are obtained for reproduction, all other things being equal.

It is, however, necessary to remark that, as one part of the cocoons contains sometimes the same gross measurement, it should not be confounded with the normal cocoons. Cocoons of an exceptional bulk are, in general, the result of two grubs united under the same envelope. Their product is known under the name of "doubles," or douppions or twin threads.

This sort of product is always inferior, as much because the beds or envelopes are almost indi. visible, as because the association in the work indicates a weakness in the subject. Notwith. standing all the attention and care given by the breeder to prevent the production of doubles, and sometimes even of triples, he must, inevitably, expect to find a certain proportion of those, the value of which is hardly one-third the price of the normal product.

There was exhibited in the Exposition an 
apparatus, contrived by an Italian silk-husbandman, designed to prevent these "douppions" in the breeding of worms.

The apparatus consists in an arrangement of cells, made of very light wood, each one of which has only the bulk necessary for a single grub. When these come to their full development, ready to spin their cocoon or ball, instead of preparing heath, shrubs, or other kinds of shelter or supports, against which the worms are to spin, this kind of cell is supplied where each insect has its own separate case, which prevents two or any greater number from uniting to make a defective product.

The Italian exhibitor is endeavoring to bring into general use this system of isolation, or cellular breeding.

The system presents, according to the inventor, other advantages, by the facility which it offers in the choice of the best reproducers, and by preventing the coupling between grubs of the same family, consanguinity having been considered as one cause of the rapid deterioration of the breed.

When the coupling has been accomplished, the females are removed, and made to lay, each in the ecell reserved for her, in such a way as to be able 
to weigh separately the eggs of each laying. This weight is not to be inferior to a certain ascertained proportion, for the eggs would then be evidently bad.

In order that they may offer good chances of success, each laying should weigh at least sixty or seventy grammes (per kilo. of cocoons), each gramme to contain 1,350 to 1,500 eggs on an average.

THE COMMON SILK-WORM. (OR ROMBYX MORI.)

The common silk-worm and the species mostly in use, and which produces by far the best silk, is born in the spring, ordinarily about the middle of May. It feeds on the leaves of the Mulberry tree, and attains its full growth in about six weeks. During that period it changes its skin four simes, and, according to M. de Quatrefages, of the French Institute, increases its weight 72,000 times.

Early in July, having reached its full development, it establishes the work-shop of its wonderful manufacture.

Placed in a comfortable and secure position, it proceeds to envelope itself in a cocoon, formed 
by a filament of exceedingly fine silk, emitted from the stomach of the insect.

It soon disappears in the center of the cocoon, or silken envelope, and, after about seventy-two hour's of umremitting labor, produces a thread ordinarily not less than 1600 yards in length.

In that chosen retreat, the silk-worm again sheds its skin for the fifth time; but the insect, which comes out is no longer a silk-worm, but a chrysalis, bearing but slight resemblance to the worm. After two weeks or more, according to the temperature, the skin of the chrysalis, in its turn, opens, and, changing for the last time, it hecomes a butterfly, lays some hundreds of eggs, and dies.

Besides the Bombyx Mori, there are other species of silk-worms that merit a hrief notice, and particularly the following:

CASTOR-OIL PLANT SILK-WORM. (BOMBYX ARRTNDIA.)

This species of silk-worm is a native of Bengal and of British India. It lives, both in its wild and in its domesticated condition, upon common castor-oil plants and other vegetation. It was but recently introduced into Europe by means of a 
few living cocoons, imported into Malta. Their propagation was not only successful, but it was continued in Italy; whence many were sent to France and to the Canary Islands.

Wherever the castor-oil plant grows spontaneously, as in Algiers, Brazil, and Rio de la Plata, the efforts to rear this species of silk-worm have been crowned with success. Its cocoons cannot be reeled in the ordinary way, but they furnish a staple, which, when spun into threads, produces fabrics of great suppleness and durability, though almost destitute of luster.

AILANTHUS SILK-WORM. (BOMBYX CYNTHIA VERA.)

This kind of worm is indigenous to the temperate regions of China, where it lives mainly on the Ailanthus.

It has long been cultivated by the Chinese in the open air, and produces an elongated cocoon of a reddish shade, furnishing a kind of Bourre de Soie, from which is made a very strong and durable tissue.

This silk-worm was introduced into Europe for the first time in 1857, and into France in 1858, 
where the first successful rearing of it is chiefly due to Madame Drouyn de L'huys.

But it is to M. Guerin-Méneville, who, under the patronage of the Emperor, experimented extensively and with success, that belongs the credit of having given to this silk its growing importance and industrial value.

THE TUSSEH SILK-WORM. (воMBYX MLITA.)

This notable insect lives in a wild state in Bengal, and in the hot regions of India, in the woods where the inhabitants go to gather the cocoons, which are remarkable for their size and form. Its favorite food is the leaves of the Jujube tree. Efforts have been repeatedly made to reproduce it in France, but in vain.

The cocoons of this insect produce a fine and brilliant silk, and very strong, known in India as Tusseh, of which large quantities are exported to Europe.

THE WILI) SILK-WORM OF JAPAN. (BOMBYX YAMA-MAY.)

This worm, raised from eggs, sent from Japan by the Consul-General of France, at Yedo, has been successfully reared. 
The oak-leaf and trees of the same kind are its only nourishment.

It does not require great heat, and is easy to raise. Its cocoon is of a greenish yellow; is formed like that of the ordinary silk-worm, and can be reeled into a beautiful silk.

BOMBYX GECROPIA.

This description of worms, indigenous to the temperate regions of North America, is found principally in the Carolinas, Louisiana, and Virginia. In its uncultivated state it lives upon the elm, the willow, and other trees. It produces a large cocoon of a loose texture and coarse silk.

At the Exhibition there was a collection of silk-worms in their different stages. A quantity of eggs, of mulberry leaves, and all that relates to the rearing of the silk-worm, were also displayed there.

The silk-worm is tender an 1 delicate. The experiences of the last twenty years have proven that it is liable to epidemics that rage with peculiar violence and fatality. 
STATE OF THE SILK-WORM MALADY AND THE REMEDIES PROPOSED.

During the period in which the disease in question has attacked the silk-worm, great research and the most minute study have been made to ascertain the cause.

Some have ascribed this calamity to the mulberry; others have compared it to a species of Asiatic cholera, or an epidemic analogous to the cattle distemper, from which England and Germany have suffered so much within the last few years.

Others have asserted that the breeder had gradually departed from, and neglected those healthful traditions and maxims so essential to be observed in the breeding and rearing of such delicate creatures.

The breeder, perceiving that he could abridge the period of rearing by raising the temperature of the nursery, prematurely matured unhealthy broods, and thence there arose numerous accidents, because, by raising the temperature, the appetite was forced, which caused derangements in the animal economy.

These different causes, more or less vague and 
indeterminate, may have contributed to the development of the epidemic. However, the theory of disease in the mulberry is hardly admissible, considering that it has been demonstrated that worms of different breeds or races, nourished ly the leaves of the same tree, have experienced different fates. Some succeeded; the others were attacked by the disease and perished. Therefore, the food in these cases was innocent of the effect.

In the difficulties by which we find ourselves involved in endeavoring to determine the cause of the malady, we have only to seek out the character and seat of the evil, to be able $a$ priori, to reject infected subjects.

After numerous investigations lyy eninent men, certain spots, or hodies of peculiar form and appearance, were discovered with the aid of the microscope in the very tissues of the diseased worms at the bottom of their digestive canal, evidently foreign to their organization, and in quantities proportionate to the violence of the disease. To these little spots, or hodies, the name of corpuscules was given. They are oval, transparent, smaller than the globules of human blood, and resemble the globules of certain fermentations. 
Widely different theories prevail in regard to these corpuscules, and the remedies required for their eradication. The listinguisher savant, M. Pasteur, has come to the conclusion that it is an organic, constitutional affection of the insect, to destroy which, either a specific remedy must be found, or else all the conditions farorable to the production of the corpuscules must he avoided, either by obtaining eggs from countries exempt from the malady, or by allowing none but healthy insects to propagate. He has demonstrated that contact between healthy and infected worms does not impart the disease; while on the other hand, the ahsorption of a few corpuscules through the feeding upon leaves washed with corpuscules water, causes the epidemic to spread with incredible rapidity.

M. Pasteur is of the opinion that search must be made for the corpuscules in the chrysatis, and he develops a rery ingenious method for facilitating the discovery. He recommends the immediate destruction of all insects known to be affected, and the separation from them of healthy subjects, and enjoins the utmost cleanliness as an essential condition to the extirpation of the disease from a silk nursery. 
M. Bechamp, who has devoted great patience to the investigation, propounds the theory that the disease is parasitic, and that the parasite is of a vegetable nature, of the order of fermentations, and that remedies, like creosote will arrest, if not destroy the development of these vegetable "cor. puscules." His mode of application is to wash the eggs in a solution of creosote, or diffuse an impregnate vapor through the rooms of the silkworm nursery.

Suffice it to say, that the methods recommended by each of these gentlemen for the extermination of the disease, have been tried, but with only partial success. But all concur in the opinion that the eggs of diseased subjects are unfit for use, and should be rejected.

It lias heen demonstrated also, that the grubs, the chrysalides, and the moths, proceeding from the Japanese race, or that of the South American States, have been, to the present moment, free from all trace of corpuscules, and all symptoms of the disease.

Practical breeders of the South of France have made very interesting experiments, from which it resulted that the worm, when hatched and bred in stables, or in sheep-folds, generally did well. 
Comparative experiments prove that the same lot of eggs, divided into two parts, gave products good in quality and quantity as to the half raised in the atmosphere of a stable, whilst the grubs of the other part, bred under the ordinary conditions, generally perished.

These repeated trials appear to demonstrate that the grave nature of the affliction can be modified by the alkalinity of the atmosphere, which developes itself in so declared a manner under the conditions of which we have just spoken.

It is a species of treatment, analogous to that of the water and salt of Vichy, and other thermal springs.

ELEMENTS AND EXPENSE WHICH ARISE FROM THE BREEDING OF SILK-WORMS.

The industry whose object is the production of cocoons, is composed of elements so special and so different from those of manufactures in general, as to require that some details be given on the subject, partly agricultural and partly manufacturing.

The basis of the labor of the silk-worm breeder 
is founded in general on the amount of mulberry leaves consumed. These leaves constitute in this case the raw material.

We will give some figures derived from localities where the population is relatively condensed, such as the South of France and the North of Italy, the principal European centers for rearing the silk-worm and the mulberry.

A hectare (or $2 \underset{1,000}{471}$ acres) of land, planted with 2,500 mulberry trees, produced annually an aver age of 5,000 kilo.'s of leaves; the expenses of all kinds for the culture of this quantity may amoint to 350 francs a year.

Then the 1,000 kilo.'s of leaves amounted to 70 francs.

The 1,000 kilo.'s of leaves support a variable quantity of cocoons. In normal years it may amount to 60 kilogrammes.

Taking the 1,000 kilo.'s of leaves as the unit the average expenses for feeding worms, for 30 grammes of eggs, are as follows:

$30 \mathrm{gr}$. of eggs, with a price very variable, are at the $\operatorname{maximum} \ldots \ldots \ldots \ldots \ldots \ldots \ldots \ldots \ldots \ldots$ Fes. $15 \ldots \$ 3$ 1,000 kilo.'s of leaves.................. " 70.. " 14 Manual labor of two persons during 40 days..... " " $160 \ldots$ " 32 Warming and lighting................. " $10 .$. " 2 Cells for cocoons, and incidental expenses....... " 5. " 1

Total. . Fcs. $260 \ldots \$ 52$ 
The fresh cocoons are now worth at least eight francs the kilo. It would be sufficient to obtain 32 kilo.'s for every 1,000 kilo.'s of leaves to pay the disbursements, and if the gatherings yield, as is usual in normal conditions, 50 kilo.'s only, this would be a gain of, 50 by 8,400 francs $(\$ 80)$; and if one worked on a basis of one hectare of land only, this would be a gaining of, 400 by 5 , 2,000 francs $(\$ 400)$ in six weeks.

There were breeders in France, who, before the epidemic, produced as many as 1,000 kilo.'s of cocoons in a single season.

TOOLS OR STOCK NECESSARY TO TRANSFER THE COCOONS INTO RAW SILK.

France and Italy are the only countries which have exhibited the apparatus necessary to transform the cocoons into threads of silk. These are the most advanced, in the whole of Europe, in this speciality.

The industry of Spain, of Greece, of the Levant, and of Russia, has imitated, as much as possible, the means used in France and Italy. Those countries have not, however, been able to arrive at the perfection of their neighbors. As to the 
Orientals, they lose a part of the advantages which their privileged climate gives them, in regard to the production of silk, by insufficiency of care and skill in details.

The implements, properly so called, for converting the cocoons, are most simple in all countries of the world. They consist principally of a basin and a reel. The basin is used to receive the cocoons, and some warm water to soften the gum of the silken-envelope, so as to set free the threads forming the external silky layers.

The union of a certain number of these threads, forms the thread of commerce, known under the name of grège, or raw silk.

The reel, by its rotary motion, winds off the cocoons.

In the factories certain number of these winding machines are placed side by side, the impul. sion being given to them by a single motive power. Of course, the arrangement is such that the operator can, at will, stop any one of these little contrivances, while the other's continue at work. The entirety of the operation is auto: matic, except that, in regard to each reel, we find a basin, and a woman to superintend the work.

The labors of the superintendent consist: 
1st. In the immersion of the cocoons in the war'm water, until the silky layers are sufficiently softened.

2d. In the cleansing, with a species of brush or broom, of the first layers until they become a pure and clean thread.

3 d. In the uniting, by pressure, and twisting a certain number of threads of the cocoons in proportion to the standard of raw silk intended to be produced.

The grege thus formed by the union of a greater or less number of cocoons, is passed through an orifice, or drawing frame, which acts on the winder, whose rotation determines the development of the threads of the cocoons which remain immersed on the surface of the water in the basin, so that, in proportion as the cocoons are wound off, the attendant is careful to add a new one, as much to keep up the supply of thread as to maintain the regularity of the standard.

The cocoons being conical from the commencement to the end of the winding, the grège would have the greatest irregularities if the workman did not conduct his work so as to connect the strongest; that is to say, the commencement of 
the thread of the new cocoon with those which are just being exhausted.

The threads, issuing wet and gummy from the basin, would adhere and stick together in the skein, if careful means were not taken to prevent it.

The preventive consists, first, in preserving a sufficient distance between the basin and the reel to permit a partial drying; and, second, in a "guide thread," so arranged that the transport takes place by a slow zig-zag movement, which prevents the threads from crossing each other at the same point at each turn, which latter causes the adhesion.

Some suggestions will assist us to understand and to obviate the difficulties in this branch of the work.

The degree of previous preparation should vary with the durability of the silky couches, having regard to the age, breed, and origin of the cocoons.

If prepared too much, the result would be that more silky matter would be yielded by the first layers than there should be. This superfluous matter would be ouly waste, and would possess a value much inferior to that of fine silk. 
If the cocoons are, on the contrary, insufficiently prepared, they present a resistance to the winding off, which causes the breaking of the thread, and leads to a new source of waste.

The workman ought to possess great skill in joining a new thread to a thread in work. He should he competent to select the most opportune moment to assure the regularity of the product, so that the trace of these successive connections may be imperceptible to the eye, and thus avoid knots, coarseness, curls, or dots.

Nor will rare skill in these particulars produce the effect desired unless the wheel rerolves with a fixed and steady relocity of at least five hundred metres per minute. Without this, the thread instead of being smooth and brilliant, would he rough and dull.

A too slow movement would not dress the thread sufficiently-clasped, as it is, very tightly by its peculiar position, and fixed under the form of the figure 8 in the layer's of the cocoons. .

A movement too slow causes those undulations which give the dull appearance; while the development of the thread in the straight line by the more rapid movement permits the reflection of the light in those perfect and determined 
conditions, which give brilliancy to the finest silk.

We have entered somewhat at length into these details, because they will assist us to discover the many different sides of a question of apparent simplicity, and will enable us the better to understand why the more perfect development of this industry remains concentrated in the hands of some populations-and why automatic labor has not been able till now to bring about those elaborate and exquisite modifications in silk which have been produced in other textile fabrics.

But if converting the cocoons into raw silk in. a successful manner be due to local circumstances, such is not the case with the industrial specialties which follow it, commencing with the "throwing" or spinning of the silk.

Almost all European nations were represented at the Exhibition by the different mechanisms employed in the silk manufacture.

Let us take a glance at the machines of this character. We will first speak of the machinery used to sort and dress silk badly reeled; and it may be well to enter into some details on this 
sulject, as it is one that particularly interests the American manufacturers.

Silk of the first quality being actually as dear as silver "ought to be employed only in the best and most perfect conditions, especially when it is intended to produce fabrics like those so much admired at the Exhibition, and among others the truly artistic silks of Lyons.

Different means have been devised to determine the standard of the silk thread. If it be pure, it will have the degree of solidity and tenacity desired. The manufacturer is particularly ingenious in constructing apparatus to rectify, sort, and dress silks of irregular standards.

APPARATUS TO SORT, TO PROVE AND TEST THE

QUALITIES AND PROPERTIES OF SILK.

Silk thread has more need to be sorted, or numbered, than the threads of other substances. The sorting or numbering is to determine the relation of the unity of weight to the unity of

* In spite of the high price, and the crisis in silk husbandry, silk costs much less than in the time of the Romans. The Emperor Aurelian refused a silk dress to his wife, assigning as a reason that it was too expensive a luxury even for a Roman Empress, silk then being sold at the price of gold, pound for pound. 
length. For silk, the unity of weight is generally the denier or fraction of the ancient livre of Montpellier, and the denier is equivalent to grs. 0.53 .

The unit of length is 400 aunes, representing 475 metres, or 515 yards. Thus, when we say a silk of 8.9 deniers, we mean that a thread of it, of 475 metres of length, weighs from 8 to 9 deniers.*

Efforts are being made to modify this standard, and to substitute the unit of 500 metres for the 475 metres, and the milligramme for the denier, in order to make the system conform to the metrical system.

The rectification of the standard of silk seems to be more necessary than that of other materials, because, from the manner silk is produced, we are far less sure to arrive at regularity than by the automatic process practiced for the conversion of cotton, wool, \&c.

Besides, as silk, from its nature and price, is intended for the dearest kind of products, the material employed in its manufacture ought to be so much the more perfect.

* Condition Publique des Soies et des Laines. Bureau de titrage. Décret du 2 Mai, 1853. 
The mode of titrage, generally used in all periods, consists in winding off a certain length, and the determination of the weight of this length. The less it weighs the finer of course will the silk be. It is evident, for example, that, if 500 metres weigh one milligramme, it will be one-half more fine than if it weighed two milligrammes, supposing, always, that its hygrometric and thermometric condition does not change during the operations. The same unit of length will weigh more if it contains humidity than if perfectly dry.

The public establishments of Europe, to ascertain the condition of silk, have for their specific olject to determine, in an exact manner, the real state of the silk, its degree of humidity, and the absolute weight of this same foreign matter, as if the silk were perfectly dry.

Establishments of this kind, it is well known exist in the principal manufacturing centers of the trade in silk and wool.

They generally operate under the direction of the various Chambers of Commerce.

These means of control offer a great security to business, but unhappily they can do nothing to verify or estallish the regularity of the threars. 
The titrage gives, in effect, only the relation between the weight and the length, but indicates nothing as to the homogenity of the thread. Each determinate length of a skein may have identical weight without the thread being regular. For example, if a skein of 10,000 metres presents an equal titre or standard, for each 1,000 metres, that would not demonstrate that upon this length there may not he parts alternately coarse and fine.

This effect happens much more frequently with the silks that are poorly worked on account of their low relative price.

Some sellers in China, Japan, and the Lerant, strive, with great persistency, to ascertain and rectify these irregularities of thread by the windings off. During this process, when the eye discovers the defects, they are removed by the hand; but this is a slow, expensive operation, and anything but sure.

The Swiss Exhibition contained an automatic apparatus which arrives much more efficiently and economically at the result sought for. 
THE SILK SORTING APPARATUS OF G. HONNEGER, SWITZERLAND.

This machine receives, on the one part, a series of skeins of silk. To each skein, correspond a number of bobbins or reels, equal to that of the varied bulk supposed to be contained in the skein.

The solution of the problem consists in collecting on each bobbin, thread of the same fineness. Let us suppose five bobbins, from No. 1 to No. 5. Each will receive the portion of thread of the titre for which it shall have been desig. nated. For this purpose, the thread which is rendered from the skein to the bobbins, is guided automatically by a mechanism for gauging, extremely sensitive, and so arranged that the grége, or raw silk in passing, acts upon a lever which directs the silk upon the proper bobbin. The variation in the bulk of the product is the point of departure in the variation of the guide-lever, which directs the thread to the reel proper to receive it.

A glance at the working of this apparatus, enables us to understand it better than would the most elaborate description. 
By the employment of this machine, the cheap silk of the East can hereafter find still more extensive applications, and contribute to a new development in silk industry.

AN APPARATUS TO TRY THREADS, BY PROF. ALCAN.

Another apparatus of great utility was exhil)ited by Professor Alcan, in the French section. It is an instrument of rare precision, very simple, not expensive, and works with great facility. Its object is to test the tenacity and elasticity of filaments and threads, and to determine the degree of tension most suitable to be employed on any given thread.

The mechanism of this instrument, though not at all complicated, lras been explained in detail, with its applications, by the inventor, in several works very popular in France, particularly in his treatise upon the textile arts, one of which is entitled a treatise "On Cotton Labor," and the other on the "Manufacture of Wool."

These works of M. Michel Alcan, Professor of the Conservatoire Imperiale des Arts et Metiers, de Paris, are to he obtained hy the publisher, J. Baudry, Paris. 
We name these works, because they give a greater amount of information upon the production of the raw material, and upon the progress of this industry, than any other works within our knowledge.

Near this machine, at the Exhilition, is another apparatus, called Expérimentateur-Phrosodynamique, to prove threads; and also a new machine to prepare and open cotton before the ginning; both the production of Professor Alcan. This eminent engineer has made, as we have seen, a special study of the industrial questions, which are of such vast importance to the American people.

\section{IMPLEMENTS AND APPARATUS USED IN SILK THROWING.}

The machines for Silk Throwing, seen at the Exhibition, have remained, as far as fundamental principles are concerned, in the same general condition wherein they were at the origin of automatic industry; but they have been improved in their details, and in the harmony of their ex. ecution.

The Swiss manufacturers, especially, have ex- 
hibited a remarkable collection of implements in this department.

The assortment, as thus exposed, and which are employed in the best factories, consists:

1st. Of a series of "tavelles," to wind, clean, and equalize the threads during their automatic winding off.

2d. Of an apparatus to unite and double the threads, with a mechanism for instantly stopping the machine whenever a thread breaks.

$3 \mathrm{~d}$. Of a machine to give the first twist to the doubled threads in the direction determined, for the production of the tram or woof.

4th. Of a second machine to retwist together, two threads already twisted separately, thus producing the organzine.

The object of these machines, so simple in their construction, is to obtain, constantly, an evenly twisted product; that is to say, worked in such a manner, that each unit of length receives exactly the same number of turns.

Now, the realization of this object was not effected without encountering difficulties, which have been completely surmounted by the Swiss and French mechanicians, judging as well from the machines, as from the magnificent threads exhibited. 
This class of machinery is the more advanced, because the machines to convert silk, are, of all others, the cheapest; and this results directly from their greater simplification.

The "throwing" the threads of silk, has several objects in view.

1st. It gives them a sufficient resistance to admit of their being boiled in soapy water to remove the gummy matter, so that they may receive the dye better, and give greater brilliancy than if they had remained in the raw state.

$2 d$. By the ungumming, the silk acquires the desired suppleuess of silks called "boiled," whilst, if it retained its gum, it would be stiff, and rough-like the silks employed in "bareges," for example.

3d. The "throwing" the silk is intended to give a certain peculiar appearance to the threads, which partly determines what is called the grain of the stuffi.

Moreover, when these threads are intended for brilliant tissues, such as satins, the two successive torsions which constitute the organzine, are combined in such a manner that the last, which will be the most apparent, should have the least twist, in order to preserve the brillancy of the stuff: 
The combination is inverted if the olject be to make threads for taffetas, Gros-grain, Gros de Naples, etc.

The work of silk-throwing, by the combination of the varied conditions it requires, necessitates the possession of such accurate knowledge, and the use of such rare skill as to constitute it a special art

SIMULTANEOUS REELING AND THROIING.

It has been frequently attempted, and is sometimes still sought, to unite in one single operation the winding off the cocoons and the throwing of the silk. Notwithstanding that, for a long time the solution of this problem, which apparently presents no serious difficulty, has been considered the Philosopher's stone of silk industry, the effort has not been abandoned. Still, in this department, as certain mechanism exhibited by the Italians and French, attest, the problem offers but little interest or encouragement, as for example :

To wind off the cocoons, and twist the thread at the same time, the raw silk or grege, in issuing from the basins, instead of being passed on to 
the reels by one simple movement, is rolled around bobbins, having a rotary motion, in order to give torsion to the threads.

It is necessary to direct two of them together upon one bobbin to produce the tram; consequently, the intermediate operations are all suppressed and condensed into one single process; and hence an apparent economy; but, in fact, this economy disappears, and the new mode becomes comparatively expensive, because the production is considerably reduced, and because it requires a much larger personal attendance.

A few figures will suffice to demonstrate this. To produce the grège, the velocity most suitable is such, that one workwoman throws out, at least, a length of 500 metres of thread a minute.

When the thread is twisted at the same time, only 500 revolutions are given per metre to it in the majority of cases. Suppose a velocity of 3000 revolutions to the spindles, only 6 metres will be produced instead of 500 a minute.

It is true a workwoman can superintend four threads instead of one, but it will still be necessary to employ twenty times as many spinners in this case as when the production of grège was in question. 
Now this augmentation of expense is much more considerable, than the economy realized by the suppression of the intermediate operations. But the most serious difficulty consists in the im. perfection of the results. The slowness of motion in the simultaneous twisting and throwing, does not permit a suitable development to be given to the thread, nor a sufficient tension for the entire unwinding, which causes the dark aspect of the product already spoken of.

In a word, by the combination of different operations, the workman is not able to bestow upon his task that care in cleansing and purifying which is performed by the automatic system and by hand, as it exists in careful silk throwing.

Thus, the apparent progress, so enticing in appearance, demands an expense much more considerable than that of the separate operations mentioned, and can only give inferior products of inconsiderable value.

In order that they may be forewarned, these facts are worthy of special notice by the American people, who are only beginning to turn their attention to this branch of industry.

However, all new attempts may reach ultimate success; and if it be true, that for beautiful nor- 
mal products, the simultaneous twisting, and throwing must be rejected, there are cases where they may be employed, and indeed where they begin to be employed, with a certain success, as for example, when the cocoons are of an inferior quality, and difficult to wind off, such as double cocoons, so that the operator in twisting them directly, can at the best, obtain silk of only an inferior grade, fit only for working common "cordonnet," (braid, binding, twist, lace, \&c.) In such case, the simultaneous process may be advantageously used. And, indeed, cocoons wound, and doubled, and twisted simultaneously, in order to make directly from them certain products intended for passementeries, or trimmings, have no need of such careful superintendence as would be required in regard to the same cocoons, when intended to produce the more beautiful silks. A single person can attend a greater number of ends (or bouts), inasmuch as these coarse articles are far less liable to break.

There are then two conditions which permit the employment of the simultaneous system with advantage.

1st. When the object to be attained is not an imperfect grège, but a cordonnet for trim- 
mings, of a sufficiently good quality, and at a price relatively high. And,

2d. In cases where the expense of hand-labor is considerably reduced in consequence of the character and destiny of the special product, one person under such circumstances, being able to produce very much more than he otherwise would by the ordinary process.

\section{PRODUCTION AND UTILITY OF SILK WASTE.}

The different transformations undergone by silk, up to this point, and those it has still to undergo, until it arrives at the state of "stuff," occasions "waste."

This waste presents itself' in different states. Those resulting from the operations which precede the torsion, offer parcels of raw filaments (agrégé) not twisted, known by the name of "frisons," or" waste from reeling cocoons.

There are frisons of different qualities, according to the period of preparation given to them, or according as they proceed from cocoons de graines, or perces. In this case the waste is more particularly designated by the name Galette, from which are made coarse silks, called fantaisie, chappes, dc. 
The waste proceeding from the different manipulations, commencing with the winding off of the grège in the throwing, and the operations of weaving, is generally composed of twisted ends, and is known by the name of bourre.

These two sorts of debris have been long utilized. They are divided, cleansed, ungummed, and then equalized by cutting, to prepare them for twisting, as we have already said. But there is another kind of waste, long neglected, and which has commenced to be utilized only since the very high price of silk, namely the chiffons, or rags of this material. Establishments of this kind are very rare. One exists in England, one in France, and a third in the United States. We have no knowledge of any other.

As to the winding of waste, we must limit ourselves to pointing out a certain progress, of which threads of this kind have been the object, as well in France as in Switzerland.

NEW THREADS OF SILK BOURRE.

We have seen in the show cases of the Exhibition of these two countries, threads from bourre (a sort of "shoddy"), which rival, in the beauty 
of their appearance, the most lustrous silks, and at one half the price.

These results are obtained by attention to details in the manufacture. All these operations have attained remarkable precision, and have been executed conformably to the indications of science, and by the application of certain preparations under special conditions. When the threads have been produced with the greatest care, from waste well purified, well combed, per fectly prepared and spun, the workman then proceeds to apply a thin layer, or coating of warm gelatine, or isinglass, to the thread when stretched and in motion.

The drying and ulterior chevillage completes the work, and imparts to the products that peculiar brilliancy so much esteemed, and that elasticity so indispensable to manufactures of this kind.

The unusual care and attention brought to the working up of "waste" have been necessitated, as we have said, by the rise in the price of this material. It is not many years since the waste, which at present sells from 12 to 15 francs, was worth only 4 or 5 francs the kilo. 
This fact alone is sufficient to justify the efforts made to utilize waste of every description.

Formerly certain sweepings of threads were thrown on the waste heap, which the workmen knew not how to unravel. But, for the disinte. gration of these, the most ingenious and effective machines have been devised.

These machines take the rag, or piece of silk at its entrance, and restore it at its exit, in the form of filaments carefully classed, in lengths and fineness proper to be submitted to the machines for decomposing the chiffon, or rag.

The inventors have not exhibited these machines from fear of imitation by countries where inventions are not protected by patents. Prussia and Switzerland are in this condition, and they are precisely the countries which would derive the greatest advantage from their use.

\section{DYEING AND SURCHARGE OF THREADS.}

We have but little to say on the dyeing of silk, so brilliant in itself, and advanced to such an extraordinary degree of perfection. No kind of material offers more splendor in this respect.

The invention of those colors derived from coal, 
has principally contributed to, or caused this revo. lution in the art of dyeing. The new materials have permitted dyers to obtain color's of unprecedented splendor, combining shades of marvellous variety, with extreme delicacy. Looking through the Exposition, we might almost say, in the presence of the results obtained in this direction, there is now nothing impossible. Still, close by the side of products so admirable in respect to dyeing, we saw, on the contrary, much still left to be accomplished. We refer to the attempts made for some time to gild and silver threads of sill. Some specimens of silk of this kind exhibited, denote processes still in a crude state, which do not yet supply any product capable of being used advantageously.

Another branch of dyeing, is, on the contrary, in a yery advanced state-sometimes too advanced. Reference is here made to the means used to surcharge silks, so as to make them gain, if one wished it, as much as one hundred per cent. upon their normal weight.

This process has an honest origin, and sometimes its applications are honest; but. it is not infrequently used for purposes of gross decep. tion. For example, when the threads and tissues 
are sold by length or hy surface, these surcharges have no other result than to give a certain appearance to the article, while the thickness of the tissue plays no other part here than that which frequently results from the stiffness of stuffs of this sort, without any detriment to the buyer. But, on the other hand, when the threads, and even the tissues, are sold by weight, it makes the purchaser pay the price of silk for a considerable quantity of foreign matter, which sometimes has not a fiftieth part the value of silk.

Nevertheless, the authors of these operations, whose main object is to give increased weight to silk, are tolerated, and even rewarded, at the Exhibition, under the pretext that they thereby aid in meeting foreign competition.

These are specious pretexts which ought to be made known.

As those efforts for facilitating the best employment of waste, are worthy to be pointed out and recommended, so, on the contrary, these reprehensible practices are to be deplored and condemned. 
THE WEAVING OF STUFFS OF ONE COLOR, VELVETY, OR PILED FABRICS.

We observed at the exhibition some plain silks made in France, Switzerland, and Northern Germany, leaving nothing in this department to desire.

The result proves, that if the automatic working of plain silk goods be not yet general, it results from special causes in the organization of the fabrics, rather than from difficulties in the execution of the work; for the perfect specimens herein before mentioned, were exhibited with the special notice that the weaving was done by motive power.

We examined with care the looms by which this result has been attained. Looms of this kind were exhibited in the English, French, and Swiss sections of the Exposition. The two latter nations have more especially applied themselves to the construction of looms intended for silk weaving, whilst the English looms, being adapted to more general use in the weaving of almost every kind of fabrics, are not as well fitted to the wearing of silk, which demands particular care and special adaptation. 
The Swiss and French also make the comettes for the tran, the ourdissoirs destined to dispose the chaine, and the arrangements for raising and advancing it on the loom. They thus have an appearance peculiarly their own. Competent men quickly observe, that, certain alterations, which influence only the proportions and relations between the different means generally used in all looms of this kind, are in this case important modifications.

These changes are especially employed in utilizing the peculiar elasticity of silk, so as to obtain from it the regularity which the interlacing of threads in silk goods demands, and also to be better able to secure cleanness, purity, and brilliancy.

By the side of the machines and apparatus of which we have just spoken, was exhibited a French machine to polish automatically these same stuffs.

This machine, alike ingenious and efficacious, possesses all the advantages of hand polishing, acting with only a little polish and in parts.

All these machines have great value and interest for American industry; and it is the same with the automatic looms for the 
manufacture of velvets, stuff's, such as plush for hats, \&c.

These automatic looms may be arranged in two classes. The one class works two pieces at one time; the other only one. Both have their special object and employment. The loom which makes two pieces at the same time is furnished with three chaines superposed, the one above the other, at suitable distances. The middle chaine is intended to supply the thread, which by the coupe, or cutting, forms the velvet surface. This middle chaine, or chaine de poil, has a much greater length than that of the other two. It is proportional to the length of the piece multiplied by the height of the duvet, and by the number of boucles or loops necessary to each of them.

The interlacements in the weaving of these three chaines are such that they form two toiles, or fabrics, between which is interlaced a certain height of the thread of the chaine. This height is exactly and automatically separated in two by the middle one, in order to supply the velvet surface to each piece, which, thus separated, is then rolled upon a roller as fast as this section is worked. 
Various articles in silk, and especially the most beautiful plushes for hats, are executed in this manner.

This system is more particularly suited to plain articles wherein the duvet, without the intervention of the baguettes, or small rings, employed in hand-weaving, necessitates a certain height, and can be employed to manufacture faconnées, or figured stuffs, and very smooth velvets.

The automatic work in smooth and fine velvets has yet only reached the extent of weaving one piece at a time. The operation is effected by the insertion of irons to determine the boucles or loops, which remain closed in the work of velvet frisé.

The iron is withdrawn when a certain number of boucles or loops are fixed by interlacements.

If, on the contrary, the object is to make velvet coupé, it is effected by cutting at the top each of these loops or boucles.

Thus, to the ordinary functions of weaving. machines, it is necessary in the weaving of velvets to add combinations which place and with draw baguettes to form the frisure on which these barguettes are placed, and act as a kuife or plane 
to cut these same loops in order to produce cut velvet.

These problems have been solved in the most successful manner by the looms at the Exposition.

It need hardly be suggested, that a personal examination of the machines above-mentioned, would give a far clearer idea of their structure and mode of operation, than could the most elab. orate description. The same may be said of the machines hereinafter noticed.

If, from plain articles we pass to striped and plaid silks, in the execution of which Scotch industry has long excelled, we shall encounter some difficulty and embarrassment in choosing from among the numerous automatic looms, now multiplied to a marvelous extent, permitting the frame to change spontaneously a greater or less number of trans of different colors. The numerous looms of this kind exhibited, demonstrate the activity and necessity of research in this direction, and also the energy with which science and skill are employed on all those problems whose solution can lead to utility and economy.

It is not only in articles of an ordinary character that this tendency is observable. It is no 
less remarkable in silks of the richest devices, and especially in the most beautiful articles of Lyons, adapted as well for dresses as for furniture.

THE WEAVING OF GRAND FaCONNÉS.

It is worthy of note that despite the increasing clearness of silk thread, these silks, so very rich in all the perfection of their manufacture, are not sensibly increased in price.

Never, perhaps, have the stuffs of Lyons displayed more taste than now. Never have they, or those of Tours, exhibited greater beauty and perfection.

Among the silks for toilette, we remark, especially in the faconnées, or figured goods, a fineness and neatness that seemed almost impossible till now, and which denote a superiority to which French industry alone has yet arrived.

There are also combinations, armures, and moirés, as the basis of tissues, demonstrating that there no longer exist difficulties in this direction.

It was sufficient to traverse the gallery of French machines to be fully impressed with these views.

Ingenuity has leen tasked in a thousand differ- 
ent ways to simplify the elements of the Jacquard loom, and render it capable of producing still more extensive results.

It secures economy in the use of the cards, necessitated by this manufacture, by diminishing the surface of holes, or trous, and of the folds which separate them, in such a manner as to make them contain more in a given surface.

Besides the cards entirely dispensed with, and replaced by a simple sheet of paper, further on there is an ingenious combination which permits the same card to serve twice successively, and to produce two different effects, and enables it also to economise at least 50 per cent. of cards.

There are savings of another kind in the automatic execution of stitching, due to the introduction of an additional organ into the frame to make facomiées le battant brocheur.

Blonde, an article in silk imitating lace, is also exhibited by both England and France. This article, made automatically, and which for years has displayed the most elegant designs, now presents devices the most capricious and seducing.

These results are attained by the combination of the net lace frame with the principle of the Jacquard frame, skillfully modified in its applications. 
Until now, manufacturers were content to vary the designs and multiply the figures; and hence a single loom of this kind produced with considerable economy hundred of bandes at once. But that was not sufficient. The industry of Calais, (the center of the Tulle and Blonde trade of France) had just created an article essentially different from ordinary lace or blonde. It was obtained by the interlacement of threads acting exclusively in the direction of the chaine in the tissues à maille, to which we have alluded. A transversal thread of the tram made a part of the tissue, the physiognomy of which, and the mode of interlacing being thus essentially modified. The modifications, proceeding from an additional cross thread, could be carried upon the riseaux from the bottom and those of the faconné at the same time.

A new and vast field thus opens to the speciality of reticular tissues, already so rich in fancy articles. Perhaps, also, this kind of stuff will pass from silk to cotton, and to other substances, and ultimately give results analagous to those of a species of gauze, which is produced, if not with great difficulty, at least with great slowness, and at considerable cost. 
The new article may probably serve as tissues for sifting flour, and all kinds of plaster sub. stances.

The mechanical means by which these results are attained, and many others, into the details of which we cannot now enter, combining with the use in a greater and constantly increasing extent, of cheap silks, demonstrates a gratifying progress in this direction.

SILK RIBBONS.

We have only spoken briefly of ribbons from a technical point of view, because this industry was represented at the Exhibition by but one loom-that for velvet sent by Mr. Joyot June.

As to the products, they were exhibited for the most part collectively, by the manufacturers of Saint Etienne, Basle, Alsace, Prussia and other countries.

Saint Etienne contains 90,000 inhabitants, and with its suburbs, gives employment to 23,622 persons, of which the greater part are women and girls. It has 15,000 looms. According to the Chamber of Commerce, the value of its productions for the year 1866 was $60,000,000$ 
francs, $(\$ 12,000,000)$ five-sixths of which was dis posed of to the United States, England, and to the City of Paris.

The Canton of Basle, with a population of 65,000 inhabitants, has about 6000 looms for the manufacture of ribbons; in the City of Basle alone, the manufacturers, many of whom are of the first order, employ from 300 to 400 hands each, while some few employ a much larger number. The United States take the largest quantity of these goods. Then comes England, whose trade in Continental silk fabrics has greatly augmented since the last treaty of commerce with France.

It was at Guebwiller, in Alsace, that steam was first employed in the manufacture of ribbons. One may see there a model ribbon factory, which employs 600 persons, and contains 200 looms, driven by a steam engine of 30 horse power.

DEPENDENCE OF EUROPEAN SILK MANUFACTURERS UPON THE EAST, AND ITS RECIPROCAL

ADVANTAGES.

In riew of the rast capital invested in silk industry, and especially in silk manufactures, by 
leading European nations, and the great numbers of their people employed in its prosecution, we may, in the presence of the crises which has overtaken their silk husbandmen on account of the prevailing malady, pertinently ask, what would have been the fate of the industry, and the condition of its employés, had not the extreme East been able to supply them with raw material in quantities sufficient to meet the exigency ?

And what advantages have not the nations of Asia derived from being thus brought into closer relations with the more elevated and advanced nations of Western Europe?

Notwithstanding the relatively low price at which they can supply their silks, they could not, a quarter of a century since, have anticipated so high a price as they are now receiving.

Nor is this the only advantage resulting to these Oriental nations from this species of traffic with the silk manufacturers of Europe. It will teach them how to bring their products to greater perfection at home, and will stimulate them to prepare them with such care, and bestow upon them such an amount of skilled labor as to draw from them all the value and profit that comport with the excellence of their nature. 
RESUMÉ AND CONCLUSION.

The manufacture of silk, as already analyzed, and as it exists in countries the most advanced in the art, embraces seven special branches of industry, viz:

1st. The rearing of the silk-worms.

2d. The filature, or reeling of the silk from the cocoons.

3d. The throwing, or spinning of the silk thread.

4th. The dyeing of the silk.

5th. The preparation of the silk threads for the looms.

6th. The weaving of silk goods.

7th. The spinning of waste silk.

These specialties, although consequent and dependent each upon the others, like links in a chain, can, nevertheless, be practiced separately, as is the case now in some countries.

We have demonstrated that some of these employments present more difficulties than others, to countries, which, like the United States, have not yet had sufficient experience therein.

America can, however, hope henceforth to excel in these industries whenever she resolutely wills it, and devotes to them that energy and 
skill which have placed her in the first rank among nations for certain of her inventions and manufactures.

Let her not be disheartened at her efforts in this branch of industry, already most prais. worthy; and especially so in New Jersey, Connecticut, New York, Massachusetts, Pennsylvania and California. But let her press on, and bring to this new enterprise, that genius of investiga. tion and energy in execution, which have at. tracted to her so much attention, and attained for her such honorable distinction, in the Universal Exhibition of 1867.

Concerning the seven industrial branches employed in the transformations of silk, four can, from this period, develope themselves without any difficulty, and soon take in America, the high position already attained by cotton industry, namely :

1st. The throwing of the silk; consisting in the employment of apparatus more simple, and less difficult to direct than the greater part of the machines in the factories of the United States.

As to the raw material, it is as easy for the United States as for England to immediately supply herself with raw silk in China, Japan, and even in the Levant, and India. 
It is by no means improbable that, at no distant day, New York will become as important a dépôt of Asiatic silks as London now is. This may be accomplished, via San Francisco, through the medium of the Pacific Railway. The raw material having thus reached New York, will be distributed, not only among our own manufacturers, but portions doubtless will be exported to foreign countries.

Let the New World take England as an example in silk industry.

In less than half a century the silk manufacture of Great Britain, (which does not produce a single pound of silk upon her own soil,) has arrived at such a degree of development, as to give employment to a large amount of capital, and to about 110,000 looms, and direct occupation to some 200,000 persons, not including those engaged in the ribbon and silk hosiery manufacture.

$2 d$. The dyeing of silk, already an established branch of American industry, needs only the encouragement to be derived from the establishment of co-operative branches to compete successfully with European skill.

The preparatory processes of ungumming, 
cleansing, and scouring, are very simple opera. tions, and can be entered upon without delay.

$3 \mathrm{~d}$. As to the regeneration and spinning of silky waste of all kinds, the United States find themselves in as good a position as most other countries, to undertake a work of this sort, inasmuch as they possess equal facilities for procuring the waste and raw silk.

Who can doubt, therefore, that this will soon become an important branch of American industry?

In the manufacture of passementerie, or trimmings, made to a great extent of this silk waste, there are employed in Paris, alone, 8,500 persons, producing annually, products to the value of about $\$ 8,000,000$.

This branch of industry throughout France, occupies more than 30,000 hands, and the entire annual production exceeds $\$ 20,000,000$. It is one of the occupations, like ribbons and laces, that employs the largest number of women and children, who earn from twenty to sixty cents per day.

The wages depend both upon the skill of the laborer, and the nature of the work. Men earn from sixty cents to $\$ 1.50$ per day. 
St. Etienne is noted for its fashionable dress trimmings; St. Chamoud for its excellent cords, braids, and stay-laces-employing about 2,000 frames, or métiers à la poupée, in weaving stay. laces alone.

Most of these articles are extensively copied by foreign manufacturers from samples obtained in Paris. A system has been inaugurated there for promptly supplying samples of all norelties in silk fabrics by the payment of a yearly subscription.

4th. With regard to the automatic weaving of plain stuffs, the United States already compete successfully with the more experienced nations of Europe.

It is gratifying to know that the looms exhibited by American constructors, have been highly appreciated for their ingenious contrivances and remarkable improvements."

There remain, then, three specialties, to excel in which, time will be necessary to obtain the experience requisite to complete success. This,

* 'The Looms exhibited by Mr. M. Opper, of New York; Mr. George ('rompton, of Worcester, Mass., and the Knitting Machine of Mr. J. W. Lamb, of Rochester, attracted special attention, and a Silrer Medal was awarded for each. 
our countrymen will indubitably acquire in due season, if they will only bring to the task their usual sagacity and proverbial perseverance. These specialties are-

1st. The rearing of silk-worms.

2d. The reeling of the cocoons into raw silk. 3d. The weaving of figured goods, more or less rich.

We will speak of these in their order.

1st. As to the rearing of the silk-worm. The most important element in this matter seems to be solved, namely, the culture of the mulberry. The various previous trials in the United States, already mentioned, have proved that large sections of the country are admirably suited to the growth of this tree, so indispensable to the rearing of the worm. And, from what has already been shown, it may be inferred, that if the breeding of silk. worms has not been hitherto entirely successful, it is probably because, that, at the periods of these early attempts, the agricultural population was not sufficiently instructed in details, and therefore failed in some essential particulars, or lacked somewhat of that patience which the French and Italian cultivators bring to this particular pursuit. 
But, with an increase of experience, daily angmented by recruits to our population from the skilled labor of Europe and China, with individ. ualities and talents the most diverse and elastic; with abundance of capital seeking investment; and above all, with our fertile and remunerative soils, and the superior climatic conditions of large sections of our country, it is not possible that new trials judiciously conducted, should fail of success.*

2d The reeling or filature of the cocoons into raw silk, which comes next in order, constitutes, perhaps, one of the processes the most difficult to teach, and especially in localities want-

* As a proof how the introdnction of this industry into a locality will enhance the prosperity of a whole people, an interesting fact may be cited from a recent French publication.

An oflicer in the French army, having seen during an Italian cam. paign, to what a degree the cultivation of the mulberry-tree and its attendani silk lusbiudry, were cnriching the population, resolved to introduce it into the little vale in the Commune of Valleraugne, where he owned an estate. Soon after the introduction, there was obtained there only some 2,050 kilo's of very poor, unsaleable cocoons. But, after a few years, 200,000 kilo's of an excellent quality were produced anuually, valued at one million of francs, $(\$ 200,000$, which sum was mostly diffused among the rural laboring popmlation of a village of 4.000 inhabitants. The work was carried on in the following manuer: 'The well-to-do proprietors gave out the silk-worm eggs to the laborers, upon the condition that a quintal (100 1bs.) of cocoons be returned for every ounce of eggs; also giving them a sufficient quantity of mulberry leaves to feed the worms hatched from the eggs, and a certain quantity more. The cocoons produced from this surplus, constituted the profit of the silk-worm cultivators. 
ing in experience in this particular branch of silk industry.

The superiority of the French and Italian silks over Asiatic silks is greatly owing to the perfection of reeling. The success of this process depends in a large measure upon the care and watchfulness of the attendant, especially so far as the perfection of the product is concerned.

The rapid analysis above made of this kind of labor, may assist us to understand the difficulty that besets this branch of the work; but we shall render it still more palpable by saying, that the most experienced workwoman can hardly pro. duce more than 300 grammes, or 12 ounces of good silk in the ordinary qualities; obtained from 5 or 6 cocoons per thread, of which the quality or fineness is from 10 to 12 deniers, being 24,000 yards per ounce.

Nevertheless, the country which produces the most skillful and careful spinners of wool and cotton manufactures, will not despair of arriving eventually at the successful production of the many kinds of silk goods so clearly within its province.

3d. Though we feel assured that the industry of the United States will soon largely 
develope itself in the wearing of plain, striped, and plaid silks; of velvets, of plain ribbons, and other silk fabrics, simple in their character; yet, we cannot conceal the fact, that long and patient study is necessary to produce articles of sufficient novelty and artistic skill to compete with European industry, and more particularly with that of Lyons, which shines with a brilliancy peculiarly its own.

The great experience, cultivated taste, and extensive knowledge of the French, have made this specialty with them a veritable art.

The employment of Jacquard looms forms the basis of success in the textile fabrics. But, although this loom is universally in use, the effects it can produce have been no where pushed to so great an extent as in France, and particularly in Lyons.

The same may be said of Calais in its application of the Jacquard to blondes, or figured silk laces.

The Exhibition proves, by products of this kind, that henceforth, to automatic labor, almost nothing is impossible.

The magnificent specimens of lace there displayed, which imitate and well-nigh rival the most exquisite and elaborate efforts obtained by 
the slow and tedious process of hand-lahor, are now the results of the motive power of steam, while the functions of the workmen are limited to a superintendence, which becomes almost a sinecure, on account of the admirable precision and perfect execution of these machines.

It is thus that fahrics, alike beautiful and useful, once ranked amongst articles of luxury, and accessible only to the wealthy, are each day rendered more available to the masses; contributing both to the prosperity of the producer, and the gratification of the consumer.

So far from despairing of ultimate success in rivaling the most elaborate and brilliant produc. tions of Europe in this department of industry, the people of the United States may take courage by the fact that already a most successful beginning has been made in silk weaving.

Paterson, N. J., and Hartford, Manchester, and Mansfield, Conn., are already noted for their extensive silk manufactures.

For many years past all the sewing silk and twist used in the United States have been of home manufacture.* The same is, in a measure,

* 'The Williams Silk Manufacturing Company of New York, exhibited excellent "Silk Twist for Sewing Machines," for which honorable mention was made-equivalent to a Diploma. 
true of Pongee handkerchiefs. Rapid progress is being made in the weaving of ribbons, braids, trimmings, fringes, and various kinds of dress goods.

More especially may Americans be encouraged to prosecute this industry, in view of the exemption of our continent from the malady among the silk-worms now prevailing in Europe.

The devastation caused by the epidemic can hardly be overestimated. The steady advance of the malady threatens to embrace within its widening circles the silk-growing countries of the East, and thus cut off one of the main sources whence European manufacturers draw their supplies of raw material.

The calamity has thrown a pall over. silk industry in all its branches. In the course of a speech on agriculture, delivered, last year, in the Corps Legislatif, M. Thiers said that the annual loss to silk culture in France, from this cause alone, for several year's, had been upwards of one hundred millions of francs, $(\$ 20,000,000$.

Mr. Andrew Murray, in an elaborate report on "Products of Useful Insects," at the Paris Exhilition, printed in the The Illustrated London Nerns, of the 6th of July, 1867, in speaking of 
the supply of graines, or eggs in the future, says: "While things jog on, as before, from year to year, the cultivator will be slow to believe it possible that a time may come when no fiesh graines (or eggs) are to be had. But the supply hangs upon a thread; when every silk country in the world shall have become infected, then the supply must cease. And we are not far from that stage. Japan and Australia are the only countries now free. When they go, the silk trade will collapse, and silk be blotted from the list of textile fabrics. That, indeed, would be a calamity which would come home to ourselves. Our silk spinners and silk weavers, our ribbon makers, our silk mercers, and the thousands who depend on these trades for subsistence, would have their occupations gone, and ruin and starvation would await a large portion of our population. Surely, to avert such a result, not only in this country, (Great Britain,) but also over a large part of the Continent, deserves that every suggestion which promises escape should be carefully considered, and surely, if by any measure, however stringent, one country could be cleansed from the infection before its spread ends in a complete extinction of the race, and so the 
threatened ruin averted, it ought to be adopted."

Unlike almost all epidemics, this does not disappear from a locality after one or two visitations, but, once established, it remains; while its virulence increases rather than diminishes. This extraordinary trait is attributed to the fact that the silk-worm, by the law of its existence, is an annual, and, therefore, has no acclimated subjects, but presents to the epidemic a yearly supply of fresh victims. And, in view of the geographical position of the United States, it may be noted, that M. de Quatrefages, an eminent French writer, who has carefully studied this subject, expresses the opinion that, contrary to the general course of epidemics, this travels Eastward. rather than Westward.

This mysterious malady, which seems destined to destroy silk husbandry in the whole Easter'n hemisphere, has not appeared in the Western.

In view of its easterly course, and with the Pacific Ocean between it and the American Continent, and with our superior climatic conditions, it is hoped, and believed, that with precaution and care it will never reach our shores.

The soils, and especially the climate, of those 
states of our Union, where the cotton plant and the sugar-cane have been wont to flourish, are peculiarly adapted to the raising of the mulberry and rearing of the silk-worms.

From obvious causes, some of the long-existing industries of portions of those States, will hereafter be necessarily modified to a noticeable extent. The culture of cotton, and the production of sugar, will not so exclusively engross the attention of their populations as formerly. A portion of their capital and labor will doubtless seek new fields for the exercise of their energies.

Are not these facts an exhortation, an admonition even, to the people of the United States, to promptly avail themselves of their Providential advantages, and, by devoting a liberal share of their resources to the production and manufacture of silk, save this important and beautiful industry from ruin, while at the same time, they advance the prosperity of their own country and confer incalculable blessings upon the world?

In conclusion, the undersigned cannot refrain from expressing here publicly, his thanks to Messieurs Arles-Dufour and Duseigneur, of Lyons, and M. Alcan, of Paris, as well as to the many prominent manufacturers and merchants in 
the different centers of industry, in Europe, whom he has visited, for their kindness in assisting to make the numerous researches which became necessary in the examination of this important and divẹrsified subject.

The works of M. Louis Reybaud, M. Pasteur, M. de Quatrefages; the archives of the Chambers of Commerce of the various cities of France, Switzerland and Germany, and especially that of Lyons, have been valuable sources of information.

The report now submitted has swelled far beyond the limits anticipated at its commencement. But, silk industry in all its branches, now grown to such importance throughout Europe; the conspicuous place it occupied in the Exhibition; its comparative novelty in the United States; and the prospect that ere long it will be firmly established and diligently prosecuted in many sections of our country, seemed to call for a careful and thorough investigation, and a full and detailed statement of facts and conclusions.

I have the honor to be, Sir, very respectfully,

Your obedient servant,

\section{ELLIOT C. COWDIN.}

To the Hox. Wilitiam H. SEWARD,

Secretary of State,

Washington, D. C. 



\section{N D E X.}

AFriCA.-State of Silk Industry in, .

PAGE

ALCAN.-Professor, Silk Thread Testing Apparatus of,

$36-37$

Other Machines of, . . . _ _ . 69

Thanks of the Author to, . . . 106

ARLEs-Dufour.-Thanks of the Author to, . . . 106

Asiatic Countries.-State of Silk Industry in, . . 36

China, . . . . . 36

East Indies, . $\quad$. $\quad$. $\quad 36$

Persia, . . . . . $\quad . \quad 36$

Syria, . . . . 30

Asia Minor, . . . . $\quad 36$

AUSTRIA.—State of Silk Industry in, . . . 35

Aurelian.-The Emperor, His Opinion of Silk in Itis Times, 63

Becunmr, M.-On the Malady Among Silk-Worms, . 54

BLONDE LACE.-Manufacture and Beauty of, . . . 88-89

C.llfforina.-Its Cocoons at the Exposition, . . 14

Excellency of its Egos, . . $\quad 15$

Its Flourishing Silk Industry, . . 15-16

Adunirably Adapted to Silk Husbandry, . 16

Caroline, Queen.-Her Robe of Georgia Silk, . . 9

Cnarles II.-IIis Coromation Robe of Virginia Silk, • 8

Chesterkield.-Earl of, His Robe of South Carolina silk, 10

CinNA._Silk Originated in, . . . . . . 1-2

Early Exportation of Eggs, . . . . . . 4

Curious Custom of the Empress of, . . . 4

State of Silk Industry ill, . . . . $\quad 36$

Cocoons.-How to Select Good, . . . . . 43

Treatment of in Recling and Throwing, . 59, 60,75

Doubles, . . . . . . . 44

Cost.-Of Raw Silk in Various Countries, . . . . 23

Of Various Elements in Silk-Worm Breeding, . 58-59

C'ROMPTON, GEORGE.LLom of, . . . . . 97

Drourn de L'Hurs.-Madame, Introduces a New Silk-Worm in France, . . . . 49

Duseigneur, M.-Thanks of the Author to, . • . 106 
PAGE

DYEING.—Of Silk, . . . . . . $40-80$

High Perfection in, . . . . . 80

Surcharging Silk Threads by Reprobated, . 80-81

EAST IndiEs.—Silk Industry in, . . . . 36

Edict of NANTES.-Effect of Revocating on France, . 6-7

Switzerland, . $\quad . \quad 7$

Effect of Revocating on England, . 29-30

EGGS.-Importance of, · . . . . . . 42

Scarcity of Good, . . . . . . . 42

Countries where Mostly Produced, . . . 42

Mode of Selecting Good, . . . . . 43-44

Egypt, Mediterranean.-Countries, State of Silk Industry in, 37

ECUADOR.--State of Silk Industry in, . . . . 16

France.-Progressive Development of Silk Industry in, , 26

Value of in 1789, . . . . . $\quad$. 26

" " " $" 1812, \quad$. . . . . . . . . 26

" " " " $" 1820, \quad$. . . . . . . . 27

" " " " 1850, . . . . . . . 27

" " " " $" 1855, \quad$. . . . . . . . . 28

" " " 1860 , and subsequently, . . 29

Superior State of Silk Industry in, . . $\quad 35$

Persons Employed in Paris on Silk Waste, . 96

Value of this Product there and in the Whole

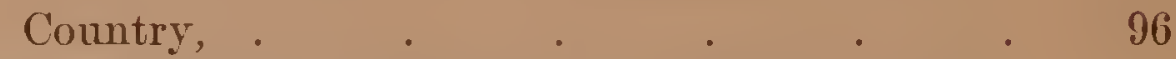

Franklin, Benjamin.-Encourages Silk Industry in the

United States, . . . 10

George III.-His Mother's Robe of South Carolina Silk, 10

GoLD.-Silk Once as Costly, Pound for Pound, as . . 63

Great Britan.-Rise and Progress of Silk Industry in, 29-33

Amount of in 1825, . . . . $\quad 31$

" " " 1855, . . . 31

" " " $" 1856, \quad$. . . . 32

" " " $" 1858, \ldots . \quad$. . . 32

" " from 1860 to $1866, \quad 32$

Superior Condition of in, . . . 33

Number of Looms and Persons Employed in, 95

Guerin, Meneville.-Introduces a New Silk-Worm into

France, . . . 70

Honegger, G.- Silk Thread Sorting Apparatus of, . 67 


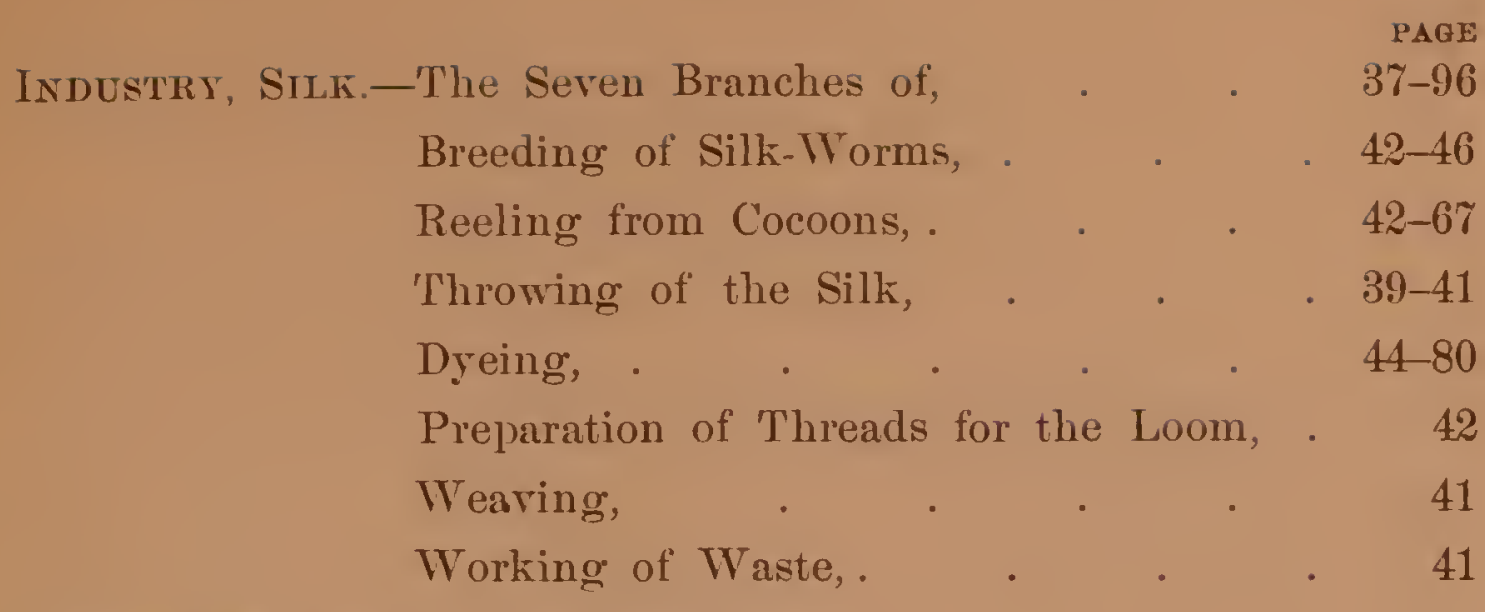

International Conference at Paris, _ _ _ _ . 21

IroN._Silk 'Thread as Strong as, . . . . . . 1

ITALY.-State of Silk Industry in, . . . . 33-34

JACQUARD, M.-Looms of, . . . . . . 88-101

Joyot, JR.-Looms of, for Weaving Ribbons, • . 90

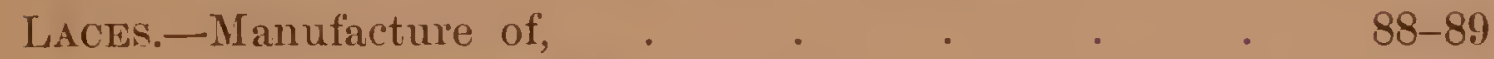

LAMB, J. W.-Knitting Machine of, . . . . . 97

LAw, Gov.-His Silk Coat and Stockings, . . 11

Lrons.-The Great Center of Silk Manufacture, · 27-28

Looms in, . . . . . . . . . 28

Brilliant Character of Products of, . . . 63

Exports of the United States in 1865 and 1866, 29

Author's 'Thanks to Chamber of Commerce of', . 107

Macinnes, Implements, Tools and Apparatus, viz:

For Preventing Double Cocoons, . . . 45

For Reeling Cocoons, . . . . $5 r-60$

For Sorting and Testing Threads, . . . 63-6\%

For 'Throwing, . . . . . . . $\quad 69-76$

For Simultaneous Reeling and Throwing, . 72-76

For Disintegrating Waste, . . . . 75

For Weaving Stuffs, . . . . . . $8 \pi-90$

For Wearing Ribbons, . . . . . 91

'The Jacquard Looms, . . . . . . . 88-101

MALADY.-Annong Silk-Worms, and Remedies proposed . 51-5j

Great Ravages of, . . . . . . . 52-103

Theories as to Its Cause, . . . . 52

Proposed Remedies, Theories of', . . . 53

M. Pasteur's Theory of, . . . . . 53

M. Bécamp's “ " . . . . 54

Facts Ascertained Concerning, . . . 54

M. de Quatrefage's Opinions upon, • • 105

Andrew Murray upon, . . . . . 103-104

Exemption of United States from, . . . 105

Morus Multicaulis.-Furor About in the Enited States, 14 
Mutberry-Tref.-Condition of its Cultivation,

Portions of United States Aclapted to, $1 \%, 18,106$

California Especially Adapted to,

$14-1 i$

MurRaY, ANDrew.-On Silk-IVorm Malady,

Nurseries.-For Silk Worm-Rearing, . . : 3i-38

OPPER, M.-LoOm of', . . . . . . . 97

PAris.-Persons Employed on Silk Waste in, . . 96

Value of Products of Waste in, . . . $\quad 96$

Pastecr, M.-On Silk-Worm Malady, . . . 5.3

Persid.-State of Silk Industry in, . . . . 36

Peter the Great.-Introduces the Mulberry into Russia, 20

Profitabieness.—Of Silk Husbandry, . • • 18

Illustration from Commune of Valleraugne, 98

* Prussia.-State of Silk Industry in, . . . . 34

Quatrefages, De.-On the Silk-Worm Malady, . 105

RAW SIIK.-Production and Characteristics of, . . 19-20

'Tahuldr Statement of 'Value, of the Product of, 23

Price at Various 'limes, . . . . 25

Implements for 'T'ransforming ('ocoons into, $\quad 63-66$

Methods of Transformation, . . . . 63-66

Apparatus to Sort and Prove 'T'hreads of, . 67

(x. Honegger's Apparatus, . . . 67

Prof: Alcan's Aplaratus, . . . . 68

ReElinf and 'Throwing. - Simultaneously, . . . 72

REVolutionary WAR.-Destructive Effect of, on Silk Husbandry in the United States,. 12

REYBAUD, Louts.-The Works of . . . . . 107

Rinbons.-The Weaving of, . . . . . . 90

Joyot's Lom for, _ . . . . . 90

Chief Localities for the Manufacture of, . . 90

Where Chiefly sold, . . . . . . 90-91

Purchases of by the United States, . . 91

Manuficture of in the United States, . 95

Russia.-State of Silk Industry in, . . . . 20

Sewing SruK.-Large Production of in the United States, 102

Sıル-Leading Characteristics of, . . . . . . 1

Name of in Various Languages, . . . . 2

Origin of in Clina, . . . . . . . . 2

Introduction into Persia, Greece and Italy, . 5

Introduction of into Constantinople, . . . . 5

Introduction of Manuficture of into Europe, 6 
SiLK.-Rise and Progress of Silk Industry in the

Enited States, . $\quad$ \%

Virginia, . . .

Georgia, . . . $\quad 8$

South Carolina, . $\quad$. 10

Pennsy]rania and New Jersey, 10

Massachusetts and Connecticut, 11

California, . . . 14

South America, . . . 16

Ecuador, . . . $\quad 16$

Sitk-Worms-Breeding of, . $\quad$. 17, 19, 42, 43, 55, 98

Habits of, . . . . . . . 44

Necessity of Good Eggrs for,. . . . 42

Nurseries for, _ . . . . . 43

Mode of Selecting Egergs for, . . . . 43-45

Male and Female ('ocoons, . . 43

Double Cocoons, . . . . . 45

Apparatus to Prevent Doubles, . . 45

Cost of Breeding, in Detail, . . . 55-57

Malady Among, . . . . . 52

Different Species of Worms, . . . 46-50

The Common Species Most in Use, . 46

Its Characteristics and Habits, . . 47

The Castor Oil Species, . . . . 47

The Ailanthus " . . . . 48

The Tusseh " " . . . . . . 49

The Japan " $\quad$. . . 49

The Bombyx Curopia Species, . . $\quad 50$

Mode in which the Worm Produces Silk, . $4 \%$

Sirver.-Silk as Dear as by Weight, . . . 63

SPAIN.-State of Silk Industry in, . 34

SPINNING OF' Waste, . 41

SPITTALFIEI.D.-The Silk Weavers of, . . . 30

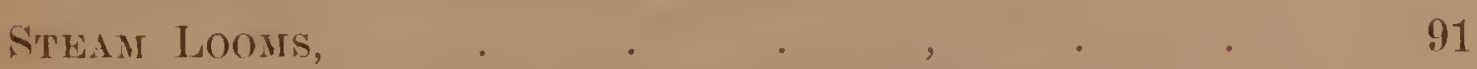

Strues, Rev. Dr.-His Commencement Silk Gown, . . 11

Switzerdand.-State of Silk Industry in, . . 35

Its Importance Next to that of France and

England, . . . . 35

Large Manufacture of Ribbons in, . 91

Variety of its Apparatus for 'Throwing, $\quad 69-70$

" " " Looms, . . . . 82 
SyriA.-Product of Silk in,

Thiners, M.-Silk-Worm Malady, . . . . . 103

Trureads.—Of Silk, Various Kind of, . - . . . 39

Thrown SiLk.-Various Kinds of Threads of, . . 37-40

'THRowiNG OF Silk.-Methods of, . . . . . 72

Apparatus for, . . . . $\quad 72$

Simultaneous Reeling. and Throwing, 72

Trmmmas.-Silk, Large Production of in the United States, 13

T'Tours.-Perfection of its Products, . $\quad$. $\quad . \quad$. 87

UNITED STATES.-Adaption of to this Industry, . 14-100

Production of Sewing Silk and 'Twist in, 12, 13,102

" " Pongee Handkerchiefs in, 103

" " Ribbons, Braids, Trimming"s,

Sc., . . . . . 108

Chief Seats of this Industry in, . $\quad .94-102$

Products of in 1840,1844, 1850, 1860 and

since, . . . . . 13

Morus Multicaulis Furor in, . . $\quad 12$

Species of Silk-Worm Indigenous in, . 50

Exemption of the Country from the

$\begin{array}{ccc}\text { Malady, . } & . & 103 \\ \text { Encouragement on that Account, . } & 105\end{array}$

The Four Branches in which they May

Now Excel, . . . $\quad 94$

The Three Branches in which they May

Ultimately Excel, . . . $\quad 94$

WASTE.-Utility, Variety and Production of, . . $\quad 76$

Methods of Utilizing, . . . . .

Manufacture of in Paris, . . . . . 77

" " " France, . . . .

WEAVING.—Of Silk Stuffs, . . . . . $\quad 82,87,88$

Frencl and Swiss Looms, . . . . 82

English Looms, . . . . . . 82

'Two Classes of Automatic Looms, . . $\quad 84$

Of Ribbons, . . . . . . . . $\quad$. 91 


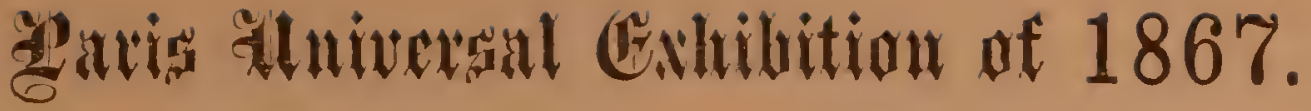

\section{AN ADDRESS}

\section{N. Y. STATE AGRICULTLRAL SOCILTY,}

AT THEIR ANNUAL MEETISG IN THE CAPITOL AT

ALBANY, FEB'Y 12, 1868,

By ELLIOT C. COWDIN.

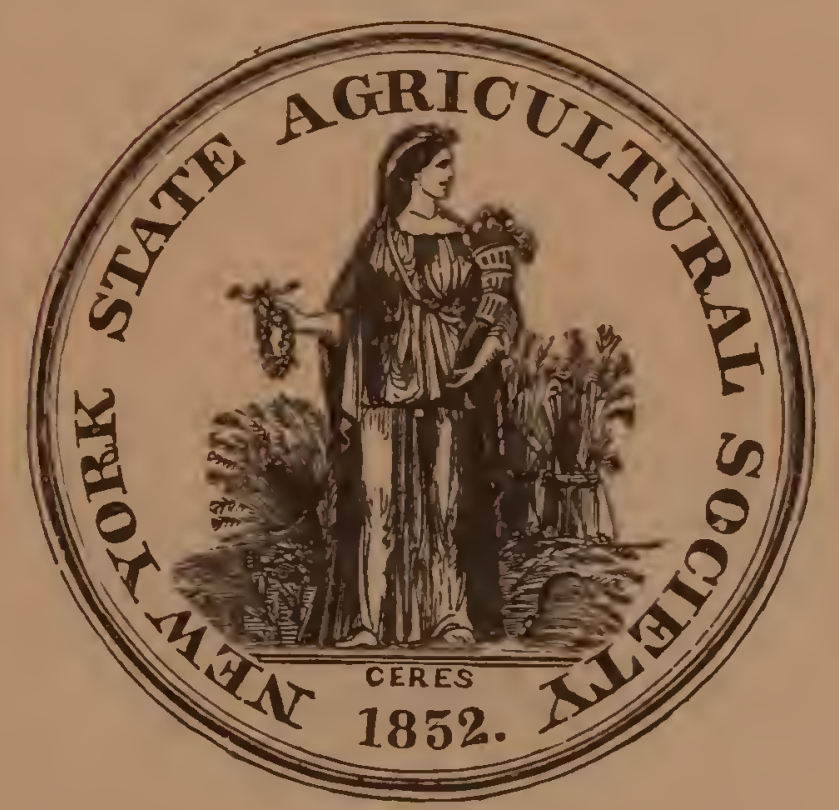

PUBLISHED BY THE SOCIETY.

\section{ALBANY :}

PRINTING HOUSE OF CHAS. VAN BENTHUYSEN AND SONS. 1868. 



\section{ADDRESS.}

Mr. President and Gentlemen:

THe opening of the past year found the attention of the world irresistibly attracted to one of its most brilliant and renowned cities, Paris, the capital of France and center of civilization in Europe.

For centuries Paris has been watched by Europe, as often in fear as in admiration. Now the entire world was led to think of it, for its gates were flung wide open, not for the exit of armed hosts pouring forth to battle and to conquest as in former days, but to welcome, with a boundless hospitality, the representatives of all nations, inviting them to bring thither and combine the products of their soil, their labor, and their art, in peaceful competition and in generous rivalry.

To the Universal Exposition of 1867 all were welcome guests, irrespective of nationality or 
of creed. It is of this great exhibition, which it was my privilege to attend as one of the Commissioners from the United States, that I purpose to speak this evening in compliance with your special request.

Paris itself is a perpetual Universal Exhibition. It epitomizes not only France, for which it is only but another name, but civilization itself.

It is a many-sided city, and each of its angles exhibits its own peculiar aspect. Hence, adapting itself to every variety of taste, it has been depicted in almost as many different colors as the chameleon. Yet every description is true, for it wears a rainbow garment. One tells you it is a city of fashion and frivolity; another that it is a city of learning, science, law, religion; a third, the focus of turmoil and insurrection. It all depends upon the standpoint of the observer, the color of the medium through which he looks, and the time of his visit. Look at Paris on a festive day, its streets and squares filled with radiant faces, and you would think that the Golden Age had been restored, and here was another Arcadia. 
Look at Paris on a day of revolution, the cannon roaring in its streets, its barricades emitting death; even women and children fighting in the ranks of battle; and you would say that one spirit of the first-born Cain reigned in those hearts. Such extreme contrasts does this wonderful city present in its history, because here all the phases of human passion and character have been exhibited as on the broader stage of the world. Here, especially, there has been a concentration of conflicting elements.

But we have now to do with happier dayswith the pacific aspect of Paris under a strong and intelligent municipal administration. It is a beautiful city, and every day growing more beautiful, for wonderful improvements are in progress, conceived in the most liberal spirit and conducted at a vast expenditure of wealth and labor. The spectator, looking down for the first time on the immense area of the city from the summit of the Triumphal Arch, or the Column of July, and contemplating the sweep of the Boulevards and Avenues, the sidewalks of which are as wide as many of our streets, the solidity and elegance of the buildings, all (without exception) of light colored stone, the lines 
of trees running in every direction, the numerous squares with their foliage and fountains, the splendid cathedrals and churches that lift their spires and domes to Heaven, the noble bridges that span the Seine, the stately columns that record the victories and glories of the past, the palaces and public edifices with their almost interminable façades, the wooded environs, dotted with villas and villages, and insulating the capital in an ocean of verdure; the spectator, I say, is lost in admiration of the scene before him, and admits that Paris is indeed the most attractive city of the world.

Descending from his airy eminence and plunging into the busy world of Paris, a unit in the sum of its life, the visitor is yet more astonished at the vitality and variety of its existence. How ceaseless the tide that ebbs and flows through its mighty arteries from sunrise till midnight! What wealth and taste in the stores that line the Boulevards and crowd the passages and arcades! Above all what order and neatness everywhere; what courtesy and civility!

The workman in his blouse manifests as much self-respect as a counselor of state or a marshal of the empire. The dignity of manhood now 
asserts itself in every individual, whatever may be his rank and calling. Parisian citizenship is regarded as much a title to honor as was Roman citizenship in the days of the great Republic. Yet there is no offensive self-assertion. The citizen claims for himself no more respect than he accords to others.

Cleanliness is another distinctive feature of the French Capital. An army of street sweepers, working at hours when their labor is invisible, remove every particle of dirt from the thoroughfares.

Those who visited Paris for the first time during the Exposition may have thought that this universal neatness was an exceptional feature, but it is not so; it is the normal condition of the city.

Of course busy preparations were made by a capital which had issued cards of invitation to the world. Buildings in process of construction were rapidly finished, and the wrecks of recent demolitions removed, that no unsightly object might offend a stranger's eye; and then, when all was ready, Paris welcomed her guests with a bright and radiant smile, giving cordial reception to emperor and peasant, citizen and king. 
Let us hasten to the great center of attraction, the Champ de Mars, the site of the Exposition, which merits a brief notice. It is a level area of about one hundred acres, in front of the Military School, and was used prior to the Exposition as a parade and drill ground, and for reviews and public celebrations.

The Champ de Mars occupies a memorable place in the history of France. On the 14th of July, 1790, it was the scene of the great Festival of the Federation designed to recall the taking of the Bastille and to inaugurate the new constitution of the kingdom.

In the center of the space rose the altar of the country where Talleyrand, then Bishop of Autun (who successively supported the Revolution, the Empire and Restored Royalty), celebrated mass.

Four hundred thousand men, women and children, occupied the terraces of green turf surrounding the ampitheatre built expressly for their accommodation. The altar and the throne. were placed side by side. The white flag of the royal troops and the tri-color of the armed populace were blended fraternally, like the masses that upheld them; and the roll of hun- 
dreds of drums and the peal of hundreds of trumpets mingled with the thunder tones of popular acclamation.

Lours XVI did not ascend the altar and swear fidelity to the constitution. He uttered the oath, and a young officer, nominated that day commandant general of all the national guards in the realm, mounted on a white horse, caught the words from his lips, rode round the immense circle, repeating them to the multitude, and then, on behalf of the king, solemnly pronounced them at the altar.

This young officer, then in the flower of manhood, the observed of all observers as the royal deputy, the central figure in the celebration, wearing a three-cornered American cocked hat, as worn by the generals of the Continental army, was none other than the friend of WASHINGTON and of Frankin, the hero of two hemispheres, the illustrious LA FayetTe.

He had left a brilliant court, a happy home and an adored bride, to offer his sword, his fortune and his life to the cause of American Independence. He returned with honorable wounds, inspired with American ideas, to participate in 
the disenthralment of his country, but not in the excesses of its revolution.

In speaking of the Act of Federation on the Champ de Mars, Everett says of LA Fayetre: "Of all the oaths that day taken by the master spirits of the time, his was perhaps the only one kept inviolate."

Dearly did he pay for his fidelity by years of suffering, but he lived to return to our own shores the honored, almost idolized guest of the nation, lived to be the controlling spirit of a second revolution in his native land, and died revered and lamented, crowned with a spotless fame.

The very year after the feast of the Federation, the Champ de Mars was desecrated by a bloody combat between the national guards and the insurgent populace, who had there planted the red flag of revolt and murder.

Well might Lamartine, in 1848, refuse, at the peril of his life, with hundreds of muskets leveled at his head in the Square of the Hotel de Ville, to accord to the maddened rioters the red flag which they then demanded, an heroic refusal, couched in words of undying eloquence. "I will refuse, even to death, this flag of blood; for the red flag which you offer us has only 
made the tour of the Champ de Mars trailed through the blood of the people in '91 and ' 93 , while the tri-color has made the circuit of the world with the name, the glory and the liberty of the country."

On the 1st of June, 1815, the Champ de Mars again witnessed an imposing demonstration, the celebration of NAPOLEON's resumption of the throne, and the consecration of the Eagles he had so often led to victory, but which he was doomed in a few days to behold stricken down at Waterloo, his last and fatal field of battle.

But the souvenirs of the scene are not all warlike. In the month of September, 1798, Francis de Neufchitteau, Minister of the Interior of the French Republic, inaugurated the first known exhibition, which was opened on the same site as that of this year, in a row of barracks containing the products of 110 exhibitors. This was modest, but in the words of the minister, "the torch of liberty was kindled," and the result has been that in the place of the humble stalls, inaugurated by Francis de Neufchitteau and his 110 exhibitors, 42,237 citizens, gathered from all the countries of the globe, displayed 
in the past year the marvels of human industry, taste and skill.

The Exposition of 1798 covered a space of twenty-seven square yards; that of 1867 occupies nearly 500,000 square yards without reckoning the Island of the Seine devoted to the display of agricultural implements. The first Exposition was exclusively French. It was only in 1848 that M. Trouvé-Chauvel, one of the Ministers of General Cavaignac, Chief of the Executive pcwer of the French Republic, conceived the idea of opening these meetings to the people of the entire world.

Political troubles prevented the realization of this project, but Great Britain adopted the plan which resulted in the erection of the Crystal Palace in Hyde Park in 1851. There in the presence of 25,000 spectators, Queen Victoria, wearing her crown and decked in her royal robes, turned to the North, West, East and South, successively, and four times proclaimed, in a loud voice, the opening of the World's Fair.

The first French Universal Exposition was held in 1855 in the Palace of Industry erected on the Champs Elysées, a spacious structure still standing, and used this year for the distribution 
of the prizes, a ceremony of extraordinary interest, to which I shall allude hereafter.

The English Fair was supposed to be a prelude to universal peace. The Paris Exhibition, on the contrary was held in the midst of the Crimean war. "It stood on its own merits, as a display of industry and of art, a temple of peace amid the clash of arms; but a temple in which it was impossible for any to worship without the intrusion of thoughts which took their color from the world without, confused as it was with mortal conflicts and teeming with political convulsion."

It is a curious fact, illustrative of the rapid changes of European affairs, that during the Exhibition of 1855 France was fighting Russia, while during that of 1867 the Emperor of Russia was her honored guest.

Although the first Universal Exhibition of England preceded a period of strife, and the first French Universal Exhibition was opened in a time of war, let us indulge the hope that this second French Universal Exhibition may be a prelude to a period of lasting peace. The erection of the Temple of Concord on the Champ de Mars is at least a fact of happy augury. 
Seen from the neighboring heights the Exposition of 1867 presented as a whole the aspect of a vast camp occupied by the representatives of all the nations of the globe. Specimens of every known architecture were crowded together in strange association; Moslem domes and minarets, Japanese huts, Swiss châlets, Egyptian temples, Turkish kiosks, and Gothic chapels. Here were broad belts of water gliding on their way, and glittering over artificial rocks in bright cascades; there a light-house and a lantern; yonder, tall chimneys and pipes, throw ing out columns of smoke and steam, and in the midst of all, the colossal mass of the main palace, built of cast iron, pierced with arched windows, and in which some visitors thought they detected a likeness to a Roman ampitheatre. But the building had really no resemblance to coloseum or palace, no pretence to architectural beauty, and only fitness to commend it.

The park which occupied nearly double the area of the palace, presented the strangest possible mixture of buildings, but in that very circumstance lay its attraction, since to afford scope for contrast and comparison, was one of the leading objects of the enterprise. 
IIere you saw a massive Egyptian templeno piece of fancy-work, but an exact reproduction. There were the vast pillars, the huge seated statues, the colossal sphynxes. Not far off was a copy of the temple of Xocchicalco, and in comparing both, you were struck by the wonderful similarity between the ancient Egyptian and the ancient Mexican ecclesiastical architecture. Farther on was a representation of the palace of the Bey of Tunis, its fanciful and graceful forms and brilliant and florid ornamentation reminding you of those glories of the Moorish Alhambra, so gracefully described by Irving. Here again you came to an Eastern caravansary, where oriental workmen were busy plaiting mats, and it required no great stretch of the imagination to fancy yourself in Cairo or Damascus. A few more steps brought you to a cavern filled with water, in which divers clothed in submarine armor, and breathing through tubes, showed how the inventive genius of man has enabled him to mingle with fishes in their native element. Then there were pavillions splendidly decorated, constructed for the special use of the Emperor and Empress, the Viceroy of Egypt and the sovereigns. 
There were churches of different Christian creeds, and buildings where Bibles and religious publications in different languages were distributed.

In the park also were buildings devoted to the display of objects crowded out of the palace or too cumbrous to be exhibited there, such as colossal statues, monster guns, fountains, pagodas.

Here the Dutch had a huge structure filled with railroad material. Belgium had a gallery of Fine Arts and an equestrian statue of King LEOPOLD. In the reserved park were foliage and flowers, and cages filled with bright plumed or sweet voiced birds, and sheets of water where gold and silver fishes sported.

Here were acquariums displaying their living marvels, strange shell fish and the wonders of the sea. In the English and: American Parks, separated by an alley, there were vast collections of railroad material. In the former there were monster guns, in the latter not a single cannon, but a better representative-the model of an American school-house.

In the Egyptian department were relics that carried the mind back in a breathless flight 
through centuries; jewels buried with the mummy of a queen of Thebes, who lived when Joseph was prime minister of PharaoH.

The supply of water from the Seine for the use of the engines in the Park, was effected by five enormous pumps, in company with the steam engine of the French frigate Friedland, which alone drew up $1,100,000$ gallons per hour. This water was received into a basin made to resemble a ruined castle, flowed into the garden, supplied all the wants of the Exhibition, formed a lake at the foot of the light-house and was finally restored to the Seine.

An international theatre, and a large hall for scientific and social meetings, were outside of the palace, together with a belt of restaurants and refreshment saloons, some of vast capacity.

The palace of the Exposition was in the form of an elongated oval. The outer circumference was devoted to machinery and was 3,936 feet in length. Then came the gallery of raw products; being nearer to the centre of the ellipse, it was necessarily shorter, and so with the succeeding zones, which diminished as they approached the inner circumference of the ellipse. In the centre of all was an open garden surrounded by statues. 
Each class of manufactures or works of art made the entire circuit of the building. The concentric rings were termed galleries. The inner circle of all, or Gallery No. 1, was devoted to works of art. No. 2, to materials for and application of the liberal arts, such as printing, books, stationery, scientific apparatus, surgical, mathematical and musical instruments, \&c. No. 3 , to furniture and other articles for dwellings. No. 4, to clothing, comprising stuffs and other fabrics worn as dress. No. 5 , to raw materials, the products of mines, collieries, forests, \&c. No. 6, to machines and apparatus and tools in general. No.7, to cereals, vegetables and other articles of food, fresh and preserved, in different states of preparation; another gallery under the name of Museum, was devoted to the history of labor. In the central pavillion of all, was a collection of coins, weights and measures of all countries. The concentric rings referred to, were traversed by avenues or streets, radiating from the centre like the spokes of a wheel. Each of the spaces thus bounded from the centre to the circumference was devoted to the products of a nation. So, that, if you wished to compare the achievements of all the nations in one class 
of productions, you followed the course of the gallery or zone round the building. If to acquaint yourself with the products of any one nation in all the branches of industry, you confined yourself to the space allotted to it, going from the centre to the circumference or vice versa. An arrangement so simple, by which order was brought out of apparent chaos, must inevitably be followed in all future exhibitions of this kind. In all former exhibitions the visitor, overwhelmed and confused by the mass of objects presented to his view, without a clue to the labyrinth, went away day after day with his head as full of incongruous articles as an old curiosity shop.

Our own country, though far from presenting its claims as forcibly as it might have done, yet made an honorable figure in the Exposition, and in some respects agreeably surprised the European visitors. That we excelled in laborsaving machinery and in useful inventions was a fact of universal notoriety; that our destructive arms and our ambulances were almost unrivaled, was also conceded; but that in the manufacture of musical instruments we challenged competition with European skill, 
and that our artists have produced works that invited European admiration, were facts known but to the select few. American art was therefore a revelation to the many, and the wonderful landscapes of CHuRch, his "Rainy Season in the Tropics," and "The Falls of Niagara;" Bierstadt's "Rocky Mountains," and HuntingTON's "Republican Court in the Time of WASHINGTON," always attracted throngs of spectators. The exquisite humor and truth of Eastiran Johnson's "Old Kentucky Home" was keenly relished, and the spirit of WinsLow Homer's reminiscence of the war, "Confederate Prisoners at the Front," was appreciated.

No foreigners, however, knew the story of the young Federal officer who-figures in that picture and gives it its interest to American eyes. They knew not that the original of that spirited figure left his bride at the altar to march to the front as a private soldier, and that he fought his way to distinction, rising from the ranks to the command of a corps.

Among the many pieces of marble statuary of modern artists, none was more admired than the "Sleeping Faun," a figure of antique grace, finely conceived and admirably executed, the 
whole wrought by the fair hand of an American girl, Miss Harriet Hosmer, of Watertown, Mass.

The magnificent American locomotive and tender, the steam engines, and machines of various kinds-some of vast capacity-attracted much attention.

"What do you deal in?" asked George THe Third of the partner of JAMES $W_{\text {ATT }}$ in the business of making steam engines.

"What kings delight in-power," was the prompt reply.

But happily that was a power which makes the people great-not their kings.

Contrast for a moment the power which the immortal WATT produced by steam, astonishing as it then was, with that of the wonderful machinery displayed at the Exposition, and how immense the progress!

If the stupendous motive power of America excited surprise and admiration, so did that wonderful planetarium which exhibited the movements of the heavenly bodies, while philanthropists experienced the purest pleasure in contemplating the Bible engraved in relief for the use of the blind, giving light to those who sit in darkness. 
A distinguished Frenchman, a great admirer of our country, who visited the Exhibition with me, expressed his views of the industrial future of the United States in nearly the following terms:

"The gallery of raw material exhibited by the great Republic must attract attention even more than her machinery, her arms and her musical instruments. Nature, in fact, has bestowed every gift upon this grand country. It reaches the icy North abounding there with furs and woods of the boreal regions. At the South it touches on the inter-tropical countries, where it finds cotton and those cultures which we call in Europe exotic. It does not lack coal. The immense extent of its territory supplies it with metals of all kinds. Its manufactures can therefore develop themselves independently of all the manufactures of the world.

"Its manufacturing liberty may equal its political liberty. It only needs," continued my enthusiastic friend, "to borrow from other countries some of their experience and intellectual wealth. Thanks to the bounties of nature," said he, "American industry can adopt the proud Italian device, 'Italia fara de se,' and say in the true spirit of independence, 'I will do it all myself." ". 
One of the charms of the Exposition was the power of ubiquity conferred upon the visitors. As in the Arabian Tales, a wish wafts a man from one country to another, so here a step took you from East to West, from North to South. One moment you were at home in America, the next you were standing in Japan; now you were in England, again in India. And it was no illusion, for everything that surrounded you was tangible and real.

"Harvest tool and husbandry, Loom and wheel and engin'ry, Secrets of the sullen mine, Steel and gold, and corn and wine, Fabric rough, or fairy fine, Sunny tokens of the line, Polar marvels, and a feast Of wonder out of West and East, And shapes and hues of part divine, All of beauty, all of use, That one fair planet can produce,

Brought from under every star, Blown from over every main, And mixt, as life is mixt with pain,

The works of peace with works of war."

Here were real Egyptian temples, and Turkish mosques, and Christian churches, and Russian houses; and you were elbowed by Turks, Greeks, Arabs, Chinese and Swedes, wearing their national costumes.

"The world was all before you where to choose." 
The English exhibitors showed great taste in the arrangement of their products.

The silk manufacturers of Manchester built up a graceful Gothic structure of bobbins decked with all the colors of the rainbow.

There was another delicate edifice made entirely of the black lead used in making pencils. This fanciful display, on French ground, was quite a success.

There was a fine collection of English decorated china, happily imitating the famous Sèvres porcelain. The English goldsmiths also had reason to be proud of their achievements. Some of the Race cups were splendid works of art.

But in machinery, cotton goods, and cheap and serviceable fabrics, the English manufacturers showed their prëeminence, and vindicated the character of England for solidity and utility. Grace is a superadded quality in their productions, an exotic, while it is the basis of every thing produced in France.

The most ordinary household article in France must be elegant at least in design, or it is comparatively valueless. Hence in articles of luxury the French defy and will continue to defy all rivalry. Fashion sits enthroned in Paris and no revolution can unseat her. 
The Brazilian display was the most remarkable of all the consignments from South America. In a vast hall the foliage of a virgin forest, with its trailing vines arching over the spectators' heads, was imitated with success.

Here were exhibited specimens of all the valuable woods, and their number is enormous; mahogany, rosewood, ebony, \&c., furnished by the boundless forests of Brazil. Elsewhere, you might behold how the skilled labor of the French transforms this rich material into splendid furniture, adorned with all the graces of art.

Let us add that many of thase splendid woods imported into France in rude blocks, after being manufactured by French artisans, find their way back to their native country changed into tables, chairs, cabinets, pianos, and what-nots, for the embellishment of the houses of the Brazilian planters or the French colonists of Montevideo.

Modern industry thus realizes the ancient fable of King Mrdas, and turns all it touches into gold.

The Spanish-American Republics did not contribute largely to the Exposition. A glance at the cases of the Central American Republics showed that the people who hold the keys of the 
passage between the Atlantic and Pacific are not a laborious and productive race.

A step carries us to the vast realm of Southern Asia, China, Japan and Siam. In these nations the arts and manufactures exhibit something of the childishness of old age. Brilliant gew-gaws, objects of luxury wrought in a style more eccentric and fanciful than artistic or imaginative, contrast most forcibly with the useful products of Anglo-Saxon genius, and show how the wave of civilization has receded to the West.

Still, however, it would be unphilosophical to fail to note how, in obedience to the laws of action and reaction that govern the universe, as the ebb and flow of the tides sway the ocean, the extreme East catches a new impulse from the extreme West. Thus the Japanese, an ingenious people, since diplomacy has brought them in communication with the United States, have adopted many of the fruits of our civilization. Commodore Perry presented the Japanese government, among other articles, with a miniature model of a railway and locomotive and a Dahlgren gun. In a very short time the Japanese, from the study of these alone, had built a railway and locomotive, and fabricated a complete battery of Dahlgrens. 
Hindostan, Persia, Egypt, Turkey and Morocco, with their contributions, made up the sum of products that fairly represented the East in the Great Exposition. They were tokens of the arts, indolence, pride, luxury and idolatry of Oriental life. Here were costly pipes, magnificent shawls, cloths of gold, rich carpets, splendid weapons of war, uncouth idols.

Half a dozen rajahs sent their most valuable effects to an exhibition to which the King of Sweden contributed pictures, the creation of his own pencil, and the Emperor of France a model of a workingman's house planned by himself.

But Peter the Great was in advance of NAPOLEON III, for he learned the trade of a ship-carpenter; and LouIs XVI was never happier than when he was displaying his skill as a lock-smith. A lock made by this unfortunate monarch was shown in the Exposition.

In general the Oriental countries exhibited the almost hopeless decadence into which they have fallen. Turkey only displays energy and vitality in those portions of her empire which approximate the Danube, and these signs of life are manifested only in a population of European 
origin. The influence of the crescent seems almost as baleful as that of the cross is benign. Egypt is also in arrears, though exhibiting more vitality than Turkey.

Next we come to Italy, whose political status is not yet firmly defined and whose manufacturing development is to be looked for in the future. Fine specimens of the agriculture of Northern Italy were displayed, but nothing remarkable in manufacturing products.

Southern Italy sent samples of the sulphurs of the famous volcanoes Etna and Vesuvius. A Roman monk, named SECCHI, contributed a self regulating apparatus for recording the range of the thermometer, the quantity of rain fallen, and the changes of wind during a given period. Left out of doors over night the machine operates of itself, and its observations are accurate.

In the fine arts, notwithstanding some remarkable productions, the decadence of Italy, from the days of the great masters, is painfully apparent. Even in the realm of music, her sceptre seemed to have passed to other hands.

Russia sent her furs, ores, minerals and cereals. Situated between Europe and Asia, 
Russia is a place of transit, though its chief city, St. Petersburg, is sealed up by ice on the water side during more than six months of the year. Moscow, the Holy City of the Greek religion, half Asiatic and half European in its character, is an immense entrepôt of raw material. Thither caravans, traversing the whole breadth of the continent, bring the costly products of China and the East. No fewer than sixty-six different races of men acknowledge the sway of the Czar.

The Russian contributions were very interesting. They exhibited a singular mixture of the East and West, of civilization and barbarism; splendid silken robes, and sheepskin garments, wooden-ware and jewelry, furs and precious stones. Here were the malachite, the onyx and cornelian from the Ural and the Caucasus; heaps of leather, splendid mosaics; and exponents of a high civilization, beautiful paintings and bronzes.

The Scandinavian countries, formerly one, but now politically dissevered, were brought together in the Exposition. These three countries, Denmark, Sweden and Norway, have many points of similitude. They are rich in 
forests, which supply materials to the hand of industry, in rosins and other natural products. Salt and smoked fish are the staple food of the people of these sterile regions, who valiantly struggle against the frowns of Nature, and in their thrift and industry, present a strong contrast to the indolence of the favored East,

"Where all save the spirit of man is divine."

These countries also contribute various fish oils used in medicinal preparations. The fishing implements of the Norwegians and Icelanders, as shown in the Exhibition, are very interesting, and show how patience and industry contend against the disadvantages of a harsh and cheerless climate.

Greece, whose glory lies in the past, contributed but little. What Edmond Aвоuт said of the Greek department in the Great London World's Fair is applicable to the Exhibition of 1867. "Honey in a pot, Corinth raisins in a jar, a little wine, a little cotton, a little madder, a handful of figs, a cube of marble, and a glass case containing a few Greek dresses." We ought in justice to add, that there were some sponges, coarse carpets, some furniture and very handsome swords and daggers. 
But we are led to hope, as a result of the Exposition, that the germs of enterprise which exist in all nations, will be stimulated to develop themselves, in those regions where they lie dormant, by the example of those countries which are marching in the van of progress.

Spain and Portugal exhibit little manufacturing energy. Agriculture is almost their only resource. The wine trade of Spain is one of the chief sources of wealth, and the making of bottle corks an important industrial employment.

The manufacturing activity of Switzerland is a powerful argument in favor of free institutions. Her valleys and lake shores are inhabited by an intelligent, well educated and industrious population. Silks, ribbons, muslins, embroideries, laces, straw braids, watches, musical boxes, and wood carvings are among the chief products of their skilled labor.

Austria is the neighbor of Switzerland at the Exposition as she is on the map of Europe. Composed of different states, having each its peculiar genius, it has no well defined manufacturing character. Vienna, the capital, is a sort of key-stone, binding the states together, and, as a place of transit, is of some importance. It had 
in the Exhibition a fine collection of articles and in great variety, many of them closely resembling those of France. Vienna receives from Paris patterns of fashions and stuffs, copies and manufactures them, and literally floods the valley of the Danube and Southern Russia with these products. For some years, however, French rivalry has considerably hampered this wholesale copying business.

Among the Austrian contributions to the Exposition were numerous specimens of that splendid Bohemian glass-ware which has long defied attempts at imitation and challenges the admiration of the world.

Next to Austria comes her rival, Prussia, and the other German States, which are only sattellites of the nation which Bismarck has raised to such European prëeminence.

Berlin, the capital of the Prussian states, is one of the principal manufacturing cities of Germany, and its leading market in the wool trade, of which article many excellent specimens were displayed at the Exhibition. Upwards of $7,000,000$ lbs. of wool pass through Berlin in a single year.

The German manufacturing system embraces almost all branches, and its expansive movement 
is to the East, where Poland and Russia, yet undeveloped countries, present a broad field for exportation.

In the Exposition there were also fine specimens of German metallurgy, blocks of salt and coal, showing the extent of its minersal resources; specimens of the color known all over Europe as Prussian Blue; superb silks and velvets from Crefeld, Elberfeld, Viersen and vicinity. Elberfeld is a Prussian city situated near Dusseldorff, in the valley of the Wipper. This industrious city owes its prosperity to the French protestants of Touraine, driven from France by the revocation of the Edict of Nantes in 1685, an act which Benjamin Constant termed "the error of Louis XIV and the crime of his council."

Belgium is the workshop of Europe, and its industry comprises almost every branch of manufacture, from the labors of the unaided hand, as in the fabrication of its exquisite laces at Brussels, to the production of wonderful machinery at Liege.

Holland, whose territory is limited, and whose chief activity is directed towards its colonies to the Southeast of Asia, sent to the Exposition specimens of the products of the Molucca Islands. 
$\Lambda$ mong the curiosities displayed were some singular Javanese musical instruments and arms.

A step further brings us to the French Department which occupies nearly half of the palace.

The industry of France embraces almost every kind of manufactured article. All, however, having the same general character, taste, imagination and elegant luxury.

Every French artisan possesses the artistic sentiment. We may smile at the assumption by a barber of the title of "Artist in Hair," and yet there is an artistic skill in his manipulations.

You remember the story of the French shoemaker, who exhibited a beautiful slipper in his window. A gentleman, who admired it, and wished to purchase the pair, enquired for the mate. "Alas! Monsieur," said the cordonnier, "there is no mate; I made that one in a moment of inspiration."

When VATEL, the great French cook, was concocting a new dish he could not be disturbed by visitors. "Gentlemen," his servant said to callers, "my master is not visible, he is composing." VAtel styled himself a composer like Rossini or Mozart.

Let us glance at French manufactures and particularly those of Paris. Parisian furniture 
is certainly prëeminently elegant. Here were chairs, tables and bedsteads, not only made of costly woods, but inlaid with ivory, marble, gold, glass and silver. There were canopied bedsteads of wonderful workmanship, the price of which would buy one of our large western farms, house, stock and tools.

Sometimes the first artists are employed to paint the panels of these cabinets and bedsteads.

When the Parisian workman has exhausted imagination and costliness, he goes back to historical models, and gives us mediæval cabinets that look like Gothic churches, or reproduces the delicate columns of the Renaissance, or the Pompadour arm-chairs of Louss XVтн's time.

The Parisian bronzes copy the most celebrated statues of antiquity, and a workman named CoLAS has invented a machine for making perfect facsimiles of these master-pieces of art on a reduced scale.

The Parisian jewelers are unrivaled, and they derive their material from the four quarters of the globe, employing the diamonds of Brazil, the corals of the Mediterranean, the opals of Honduras, and the pearls of Ceylon.

But French silk fabrics are specially conspicu ous and of surpassing beauty. 
The processes of manufacturing silk were for more than two thousand years unknown in Europe. The article was introduced at Rome in the days of Ponpey and Julius C esar, but being brought by caravans from China, its price was so high when it reached the banks of the Tiber, that it was often sold for its weight in gold.

The Emperor Aurelian, on returning from the East in the pride of victory, refused to his wife a silk dress, assigning as a reason that it was too great an extravagance even for a Roman Empress.

An imperial edict of China forbade the exportation of the eggs of the silk worm under pain of death. About the year 552, however, two Persian monks who had lived a long time in China as missionaries, and were acquainted with the rearing of silk worms, stimulated by the gifts and promises of the Emperor Justinian, succeeded in conveying a large number of egg's concealed in hollow canes to Constantinople, where they watched their hatching and the development of the butterflies. The experiment was successful.

According to a current legend, however, this was not the first successful attempt to carry silkworm eggs out of China. A certain Chinese 
princess, betrothed to a king of Khotan, brought from her father's court to her new home a number of eggs concealed in her hair. This event is said to have happened about one hundred and forty years before the Christian era. We are not told what style of hair the ladies wore so long ago, but if the chignon or waterfall of the present day was then in vogue, the princess might have smuggled eggs enough to stock a province with silk worms.

The silk worm is a very modest artisan. Born in the spring, ordinarily, about the middle of Nay, it feeds on the leaves of the mulberry tree, and attains its full growth (being the size of the little finger of a child of twelve years) in about six weeks. Small as it is, according to M. DE Quatrefages of the French Institute, it weighs 72,000 times more, at its full development, than when hatched from the egg.

Early in July it establishes the workshop of its wonderful manufacture. Placed in a comfortable position, it proceeds to envelope itself in a cocoon formed by a filament of exceedingly fine silk emitted from the stomach of the insect. It soon disappears in the centre of the cocoon, and after about seventy-two hours of unremitting 
labor, produces a thread frequently not less than 1,600 yards in length. The silk is obtained by winding off the thread which forms the cocoon. The silk worm undergoes a transformation in the center of his dwelling, into a chrysalis, and then works its way out at one end of the cocoon, becomes a butterfly, lays some hundreds of eggs and dies.

At the Exhibition a collection of sills worms attracted universal attention. A quantity of eggs, of mulberry leaves, and all that relates to the raising of silk worms, were also displayed there.

Some of the finest cocoons of all were from California, and from the most reliable information it is safe to predict, that at no distant day our Pacific coast will become one of the first silk-raising countries of the world, rivalling even China and Japan. There are now in Southern California upwards of 10,000 flourishing mulberry trees, and some 300,000 of the finest cocoons have been produced there the past year. The silk manufacture was commenced at Lyons in 1520 under the auspices of Francis I. This city, the headquarters of the silk manufacture, at one time exported $\$ 45,000,000$ worth 
annually. Latterly the epidemic among the silk worms, and to some extent the changes of fashion, have severely injured this industry. The loss by this disease to France alone, M. Thisrs has estimated at upward of 100,000,000f., or $\$ 20,000,000$ in gold annually. Our own country thus far is entirely free from it.

Before leaving the subject of French industry let us consider for a moment the prodigious activity of the great capital. Paris, with a population of $1,700,000$ souls, has more than 100,000 manufacturing establishments, doing a business of $\$ 675,000,000$. This immense industrial activity occupies 417,000 paid workmen and 133,000 small employers who also labor with their hands, making a total of 550,000 working people-comprising a body of men whose creative genius and artistic skill is scarcely more admired by the world than their political power and example is dreaded by ruling despots.

As the whole industry of the world was represented at the Exposition, Agriculture, of course, presented its claims to attentive study-agriculture, the basis of civilization, the breath of national life and prosperity.

Some of its products appeared in the Champ de Mars, but the Island of Billancourt, at a short 
distance in the Seine, was specially devoted to an agricultural display.

I shall not attempt to enlarge upon this branch of our subject, but barely glance at the salient points presented in the Exposition so far as they relate to European countries.

French agriculture is notable for the diversity of its products. At the Exposition France exhibited fine specimens of grain, hemp, flax, hops, tobacco, different kinds of woods, manufactured and unmanufactured, beet-root sugar, and wines, brandies and liquors so famous throughout the world.

There was a good display of agricultural tools and small well-made machines of moderate cost, the land of that country being so minutely subdivided that ponderous and costly machinery is in little demand.

With a population of $38,000,000$, there are $24,000,000$ who share in the ownership of the soil,* mostly in so minute spots, however, as to afford but narrow scope for either capital or skill.

The exhibition of live stock, horses, cattle, sheep and swine, was creditable to France. Merinos, Dishly and South-down sheep have 
been successfully acclimated. She produces fine horses, both light and heavy draught, and there has been a judicious introduction of foreign bloods. The live stock of other countries was excluded from the Exhibition on account of the prevailing epidemic among cattle.

Great Britain has long been famous for the high pitch to which she has carried agricultural pursuits. But, unlike France, her soil is monopolized in the hands of some 30,000 proprietors; and the condition of her farm laborers is far from enviable, actually subsisting, as some of them do, on bread and lard.

The London Punch once hit off this state of things, in a style of humorous exaggeration, by representing a farm hand at an agricultural fair - a gaunt skeleton, with the bores protruding from his skin, standing beside an enormous Suffolk hog, depicted as a bloated mass of flesh, and suggested prizes for farm laborers as well as for fatted swine.

She displayed at the Exposition a number of excellent agricultural implements, plows, threshing, reaping and mowing machines, \&c., inferior, it is true, to our own, but solid and serviceable. She contributed also a superior collection 
of cereals, preserved meats, and an assortment of wood from her colonies.

Busy little Belgium and industrious Holland sent to the Exposition samples of their flax and hemp. Switzerland sent wheat, barley, potatoes, plants for forage and hay. Spain-flax, hemp, saffron and wool. Portugal was represented by rice, corn, wool and silk. Greece, by cotton, flax, oil and wax. From Turkey came tobacco, cotton, silk cocoons, madder, goat's and camel's hair, opium, senna and various gums.

Italy, once foremost in European civilization, and which, let us hope, is now starting on a fresh career under the inspiration of independence and unity, sent fine specimens of cotton, hemp, maccaroni, rice and preserved fruits.

The French colonies of Algeria contributed good specimens of corn, cotton, wool, flax, mad der, silk cocoons and two plants, the alfa and diss, which promise to be valuable additions to the materials for making paper.

The great central and northern nations made a creditable display. Austria contributed hops, wool, silk cocoons and tobacco. Bavaria, where 43 per cent. of the people are farmers, hemp, flax, hops and tobacco. 
It may be noted in passing that agriculture is steadily advancing in all the German states. In the Rhenish provinces alone there are 162 agricultural societies, 61 of which were formed in 1866.

Colossal Russia, which is also making great improvements in agriculture, sent excellent samples of hemp, flax, goat's hair, wool, tobacco and specimens of Black Sea wheat from the vast fertile region which has been termed the granary of Europe; while Denmark and Sweden exhibited in the agricultural, as in other departments, proofs of intelligent industry.

In a word, for I must forbear further details in what at least is but a dry catalogue, the Exposition offered gratifying evidence that European agriculture from the North Cape to the Rock of Gibraltar, and from St. George's Channel to the Hellespont, is making steady progress, and that in no particular is the advance more marked than in the social improvement of the actual tillers of the soil. May we not hope that the day is not far distant when, cheered by our example, they, like the independent freemen of our own country, shall be-

"Men ! high-minded men, Men who their duties lnow, And know their rights, and knowing dare maintain." 
The marvels of the Exposition, which one brief hour permits us merely to touch upon, whose catalogue occupies two bulky volumes, attracted to Paris an immense concourse of people from all parts of the globe.

Obeying the universal impulse, sovereigns left their palaces and, like their subjects, took the shortest road to the Champ de Mars.

In this connection I should mention the sitting of the Iyternational Monetari Conference during the Exposition, attended by eminent men from most of the civilized countries, to consider the policy of unifying the coins of all nations, over which Prince Napoleor presided. The United States were there represented by the Hon. Sayuel B. Ruggles, whose able report to our government is now attracting world-wide attention.

In the palmiest days of Napoleor I, he wrote to his friend TaLma, the tragedian: "Come to Erfurt and you shall play to a whole pitfull of kings." NApoleor III might readily have furnished such an audience at Paris in 1867. - Two emperors, eight kings, a sultan, a viceroy and six reigning princes were his guests during the $\mathrm{E}_{\mathrm{x}}$ position. But he who most riveted the attention 
and excited the emotions of that vast concourse was neither monarch nor prince, but the man of ideas; a statesman, by whose genius and will a colossal confederation was created out of the ruins of kingdoms and principalities, based on national unity, and which renders illustrious the name of Otto von Bismarck.

The Sultan of Turkey and the Emperor of Russia especially engaged public attention, but not for the same reason. The attempt to assassinate the Czar by a Polish refugee caused great commotion in the capital, and we can well understand why the French Emperor, accustomed though he is to conceal his emotions, after waiting on the departing guest and seeing him safely seated in the railway train on his journey home, could not help rubbing his hands with delight at the thought of having got rid of the responsibility that weighed upon him. He is said to have remarked: "To receive an imperial guest is one thing; to have him die on your hands is quite another affair."

As for the Sultan, he excited among the populace as much curiosity as Brigham Young would have done, and for the same reason, the presumed extent of his matrimonial felicity. A lady once 
asked Taluerrand if the then Sultan of Turkey was married. "Very much, madam," was the reply. The French government papers, however, hastened to assert that the present Sultan, ABDur Azzis, had repudiated polygamy and was the husband of one wife only. A still more curious and questionable story formed a part of the current gossip. In 1798, a young French creole lady of Martinique, on her way to France, was driven by contrary winds into the Mediterranean, taken by Algerian corsairs and sold as a slave to the Sultan Selin III, whose favorite she soon became. She had a son, whowas the grandfather of the present sultan. Now, the story goes, that this pretty creole was cousin-german to M'lle Tascher de LA Pagerie, another creole, who became the Empress Josephine and grandmother of NAPOLEON III. It results from this history that the Emperor of France and the Sultan of Turkey belong to the same family.

The presence of so many strangers gave unusual splendor to the distribution of prizes, which took place in the principal hall of the Palace of Industry, a vast building erected for the exhibition of 1855 in the Champs Elysées, the finest promenade in Paris, perhaps in the world. 
The walls of the building are of stone. The shape is that of a parallelogram 820 feet long and 354 feet broad. The roof is arched, and formed of iron and glass; the height, from the floor to the center, is 108 feet.

The prizes were divided into five classes. The grand prizes, costly gold medals, few in number, were bestowed on works of extraordinary merit. Gold medals (of less value) were awarded to the highest order of industrial art; silver medals to those of a high order; bronze medals to meritorious works; and lastly, honorable mentions, equivalent to diplomas.

But there is something more highly appreciated than any of these, the ribbon of the Legion of Honor, to win which thousands have made the greatest sacrifices. It is conferred alike upon those who have won glory on the field of battle, on those who have distinguished themselves by public services, great inventions, valuable manufactures, or by acts of humanity or philanthropy. Thus the statesman, the divine, the soldier, the artist, the fabricant and the philanthropist may each merit and receive the decoration.

The Legion of Honor was instituted by NAPOLEON I. It has its staff, its officers of every grade 
and its private soldiers, who are styled chevaliers, and may be met at almost every step in the street. They are recognized by a small red ribbon attached to the buttonhole of the coat. The manner in which it is folded indicates the legionary rank of the wearer.

Every French prince is invested with the order at his birth, and all the sovereigns of Europe receive it as a compliment from the ruler of France on their accession to the throne.

With these single exceptions it is a distinction won by merit alone, and as such entitles the wearer to respect.

Proud of our republican simplicity, and educated as we all are in a contempt for glittering gew-gaws of courts with their stars and collars, often the emblems of servility or the rewards of degrading services, it is but just to say, that in France this order of civil distinction has appealed most successfully to that love of personal glory which is so characteristic of the French people.

It is a gratifying fact that to the exhibitors from our own country was awarded a greater proportion of prizes than to those of any other nation. The United States itself was honored, above all, for its contributions from the Quartermaster's 
Department and Coast Survey, they being classed "Hors concours," and pronounced wholly unrivaled.

As a mark of special consideration, the rank of Officier of the Legion of Honor was conferred by the Emperor upon the Hon. N. M. BECKwIth, Commissioner General and President of the United States Commission. The Cross of Chevalier of the Legion of Honor was also conferred by the Emperor upon several other Americans. Five grand prizes were given: one to Mr. Cyrus W. FIELd for the Atlantic telegraph cable; one to Prof. Hughes for the printing telegraph system; one to the U. S. Sanitary Commission, whose admirable collection was made at the sole expense of Dr. Thomas W. Evans; one to Mr. WM. C. Chapin, of the Pacific Mills of Lawrence, Mass., for the superior plan, organization and management of that establishment, and for promoting the material, moral and intellectual wellbeing of the operatives; and one to Mr. C. H. McCormick, of Chicago, Ill., for his reaping machine, after a thorough trial on the model farm of the Emperor, and in his presence.

Eighteen gold medals were awarded for our pianos, fire-arms, reaping and mowing machines, wood-working, type-dressing and sewing ma- 
chines, a steam engine, a locomotive and tender, cotton, minerals and artificial teeth. Seventy-six silver medals were given to us for our scales, power looms, edge-tools, machine tools; steel plows, cabinet organs, bronzed iron ornaments, microscopes, astronomical instruments, cloths, muslins, cotton thread, boots and shoes, a brick machine, a buggy, a phaeton, a landscape painting, works for the blind, tobacco, sugar, hams, \&c., \&c.

Besides these, ninety-eight bronze medals were awarded to us, and numerous honorable mentions were made.

The festival of the distribution of rewards, of which our countrymen received their share, was unquestionably the most splendid pageant of modern times. Those who have had the fortune to witness in the great capital many grand fètes and reviews-monarchial, republican and imperial-and to attend balls and receptions given in honor of eventful days and distinguished personages, will affirm that not one of them approached this in magnificence and impressiveness.

The Emperor and Empress of France, Prince Napoleon and Princess Clothilde, the Princess Mathilde, the Sultan, the Prince of Wales, the 
Prince of Prussia, the Prince of Orange, the Prince of Saxony, Prince Humbert of Italy, and their suites, were driven to the Palace in the great state coaches built for Louis XIV and carefully preserved at Versailles, all of them regilded for this occasion.

In the great hall where the distribution took place were 18,000 spectators. It was resplendent with the uniforms of ambassadors, marshals, senators and other officials of high rank, while all the invited guests were in full dress; that is, in black dress coats, pantaloons and vests, with white cravats and white kid gloves, as specially requested on the cards of invitation. The ladies were also attired as for a grand party.

In the center rose a pyramidal mass composed of those productions which had been pronounced worthy of reward.

At the entrance of the sovereigns, a band of 1,200 musicians struck up a triumphal march composed for the occasion by the venerable RosSINI, with the accompaniment of pealing bells and detonating cannon. The effect of this storm of musical thunder, as it rolled through the vaulted hall, was indescribably grand.

The distribution of rewards was made by the, Emperor in person. His brief speech, with which 
all of you are familiar, was well conceived and expressed, and spoken in a clear, shrill voice. It was heard distinctly by at least two-thirds of the immense assemblage.

Though the Emperor distributed the prizes, there was one exception. It was discovered that he himself was one of the fortunate exhibitors, and a medal was decreed to him for his model of a workingman's house.

In this dilemma, the little Prince Imperial (now eleven years old) came to his rescue, and stepping forward, gracefully bestowed the prize upon his father.

The ceremony ended by the Emperor and Empress, and Prince Imperial, the rest of the NAPOLEON family, and the royal guests of France, making the entire tour of the hall.

When the imperial party was passing the eligible spot by the side of the foreign ambassadors where were placed the Commissioners of the United States, one of our countrymen, a soldier in the late war, wearing his uniform as Colonel, mounted a bench and called for three hearty American cheers for the Emperor and Empress. Without discussing the taste and propriety of the act, suffice it to say that such a shout went 
up as only American lungs can produce; and the usually impassive face of the Emperor brightened, and the Empress smiled, as they acknowledged this spontaneous tribute of respect to the ruler who was offering the hospitality of his country to the whole world.

I have rapidly placed before you, Mr. President, and gentlemen, as well as I was able, the principal features of the World's great show of 1867 as it impressed my memory.

The vastness of the theme renders all attempt at minute description unsatisfactory. Every visitor you meet has his own story to tell, but few if any left the Exhibition with a feeling of dissatisfaction.

Certainly no one, however well informed, could have studied that display of the industry of all nations without learning much that was new to him. Nor could one fail, after such a study, to be convinced of the certain progress of humanity, continually rising to a higher plane and moving onward to a brighter future.

The Exhibition of 1855 was held when France was engaged in a deadly struggle with the mightiest power of Europe.

War could not paralyze the arm of peace. Even then, with the din of arms resounding in 
the East, the Emperor said: "In view of the many marvels displayed before our eyes, the first impression is a desire for peace. Peace alone can further develop the true products of human intelligence. You must then all wish like me for this peace to be prompt and durable."

The Exhibition of 1867 was held in a time of peace, though the political skies of Europe are never clear, and the war cloud even then was imminent.

One of the most significant and gratifying features of the Exposition was, that the representatives of the foremost states of the globe there met to give pledges to the cause of international amity and social progress: a grand congress of nations convened to secure good-fellowship among all civilized peoples, with agriculture, science, art and commerce officiating as envoys extraordinary. The remark of CICERo, that all liberal arts have a common bond and relationship, was never more beautifully exemplified than on this occasion, when France, Prussia, Russia, Austria, England, Italy and the United States, each of which had so recently astonished the world by its prowess in arms, were now seen devoting their genius, skill and resources to stimulating 
the rivalries of peace rather than provoking the perils of war. Mingling with their representatives on terms of equality, were those of the smaller powers of both hemispheres, all vieing with each other to promote peace on earth and good will to men. This sublime spectacle has doubtless done more for civilization and the concord of the world than could have been accomplished by many years of the more formal and perhaps less sincere labors of the ripest statesmen and acutest diplomatists of the age.

It is gratifying to know that in this grand congress our country played a leading part. Encouraged by this fact, as well as by the vigor and elasticity of our institutions, tested and proved by recent trials, we may anticipate for her a glorious future.

The only disturbing element in our midst having passed away never again to return, we may reasonably hope that our fertile fields will never again be reddened by blood.

No foreign foe will ever dare to set foot upon our soil. We may, therefore, devote all our energies to the cultivation of the works of peace-to the arts and sciences, agriculture, commerce and manufactures. 
Let us, then, "study to be quiet, and to do our own business, and to work with our own hands."

The time will come when we shall equal the most advanced nations of Europe in every material branch of art and industry.

Hitherto we have devoted our energies principally to the useful and the practical, and in this we have distanced Europe. Without losing sight of these, as we grow in wealth and taste, let us strive to compete in articles of elegance and luxury with those countries whose civilization and progress are the growth of ages. 


\section{,}




